\title{
Resilient Water Infrastructure Design Brief
}
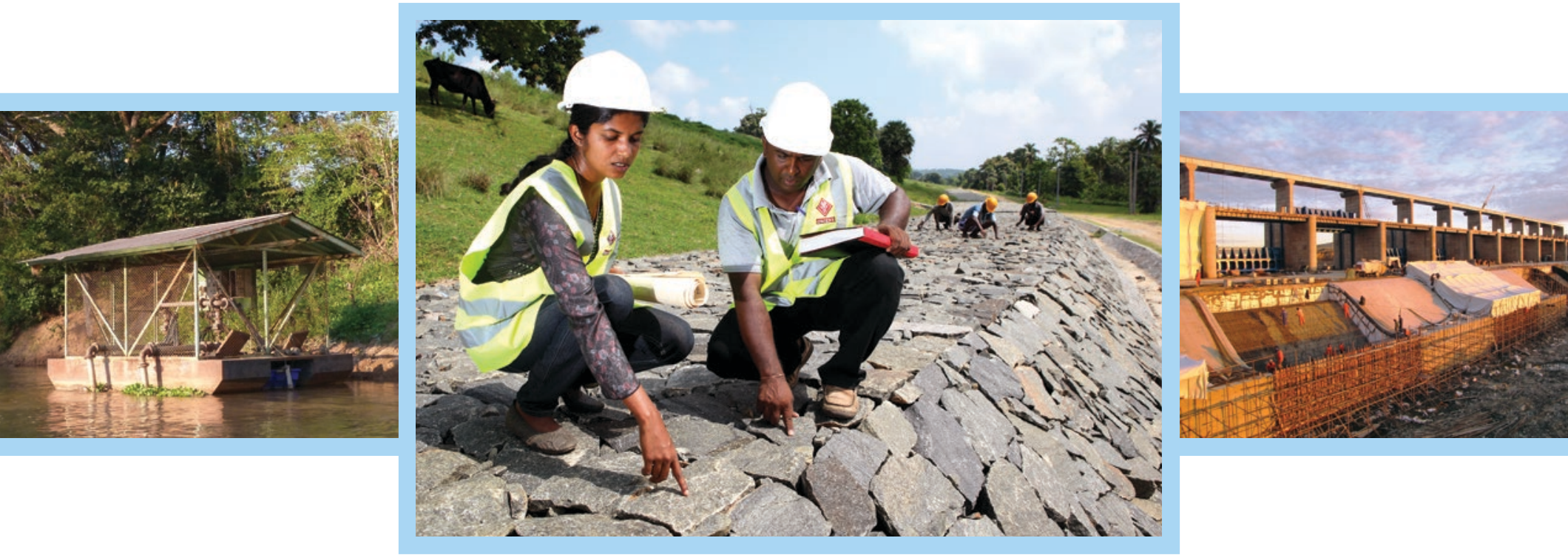


\section{About the Water Global Practice}

Launched in 2014, the World Bank Group's Water Global Practice brings together financing, knowledge, and implementation in one platform. By combining the Bank's global knowledge with country investments, this model generates more firepower for transformational solutions to help countries grow sustainably.

Please visit us at www.worldbank.org/water or follow us on Twitter at @WorldBankWater.

\section{About GWSP}

This publication received the support of the Global Water Security \& Sanitation Partnership (GWSP). GWSP is a multidonor trust fund administered by the World Bank's Water Global Practice and supported by Australia's Department of Foreign Affairs and Trade, the Bill \& Melinda Gates Foundation, the Netherlands' Ministry of Foreign Affairs, the Rockefeller Foundation, the Swedish International Development Cooperation Agency, Switzerland's State Secretariat for Economic Affairs, the Swiss Agency for Development and Cooperation, the U.K. Department for International Development, and the U.S. Agency for International Development.

Please visit us at www.worldbank.org/gwsp or follow us on Twitter \#gwsp. 


\section{Resilient Water Infrastructure Design Brief}

(4) WORLD BANK GROUP 
(C) 2020 International Bank for Reconstruction and Development / The World Bank

1818 H Street NW, Washington, DC 20433

Telephone: 202-473-1000; Internet: www.worldbank.org

This work is a product of the staff of The World Bank with external contributions. The findings, interpretations, and conclusions expressed in this work do not necessarily reflect the views of The World Bank, its Board of Executive Directors, or the governments they represent.

The World Bank does not guarantee the accuracy of the data included in this work. The boundaries, colors, denominations, and other information shown on any map in this work do not imply any judgment on the part of The World Bank concerning the legal status of any territory or the endorsement or acceptance of such boundaries.

\section{Rights and Permissions}

The material in this work is subject to copyright. Because The World Bank encourages dissemination of its knowledge, this work may be reproduced, in whole or in part, for noncommercial purposes as long as full attribution to this work is given.

Please cite the work as follows: World Bank. 2020. "Resilient Water Infrastructure Design Brief.”

World Bank, Washington, DC.

Any queries on rights and licenses, including subsidiary rights, should be addressed to World Bank Publications, The World Bank Group, 1818 H Street NW, Washington, DC 20433, USA; fax: 202-522-2625; e-mail: pubrights @worldbank.org.

Cover photos: floating pumping station on the Nan River, Thailand, François Molle; dam under construction in Sri Lanka, Lakshman Nadaraja / World Bank; construction of Intumak Dam on the Nura River, Kazakhstan, Shynar Jetpissova / World Bank.

Cover design: Jean Franz, Franz \& Co., Inc. 


\section{Contents}

Acknowledgments

Objective: Resilience

Hazard Types

5

Flooding

5

Drought

5

High Winds

The Principles of Resilient Design

Six Steps to Resilient Infrastructure

Step 1. Identify System Components and Conduct High-Level Hazard Screening

Step 2. Understand the Role of Each Component in the System and the Consequences of Failure

Step 3. Identify and Assess Component Failure Modes

Step 4. Evaluate Hazard Levels and Compare Them with Component Failure Modes

Step 5. Identify Component Risk Mitigation Options

Step 6. Evaluate and Select Component Risk-Mitigation Measures

Appendix D Sample Resilience Design Module and Task Descriptions for Use in Feasibility Studies and Engineering Terms of Reference 


\section{Boxes}

1. Resilient Water Utilities and Resilient Water Infrastructure-in Three Phases 2

2. Examples of Soft Measures to Improve Climate and Disaster Resilience

\section{Figures}

1. Relationship between the Road Map (phases 1-3) and the Design Brief (steps 1-6) 3

2. The Process of Resilient Design for Water Infrastructure Components 9

3. Schematic of A Drinking Water System 12

4. Basic Layout of A Water Treatment Plant 15

\section{Tables}

1. Types of Flood Damage to Components of Drinking Water Systems 25

2. Types of Flood Damage to Components of Wastewater Systems 26

3. Types of Drought Damage to Components of Drinking Water Systems 26

4. Types of Drought Damage to Components of Wastewater Systems 27

5. Types of Wind Damage to Components of Drinking Water Systems 27

6. Types of Wind Damage to Components of Wastewater Systems 28

7. Risk-Mitigation Options Available for Drinking Water System Components Exposed $\begin{array}{lr}\text { to Flood Hazards } & 29\end{array}$

8. Risk-Mitigation Options Available for Wastewater System Components Exposed $\begin{array}{ll}\text { to Flood Hazards } & 30\end{array}$

9. Risk-Mitigation Options Available for Drinking Water System Components Exposed $\begin{array}{ll}\text { to Drought Hazards } & 30\end{array}$

10. Risk-Mitigation Options Available for Wastewater System Components Exposed $\begin{array}{ll}\text { to Drought Hazards } & 31\end{array}$

11. Risk-Mitigation Options for Drinking Water System Components Exposed to Wind Hazards 32

12. Risk-Mitigation Options Available for Wastewater System Components Exposed to Wind Hazards 


\section{Acknowledgments}

The Design Brief was prepared by a team coordinated by Nathan Engle (Senior Climate Change Specialist) and including Daniel Medina (Consultant), Greg Felter (Consultant), Diego Rodriguez (Senior Water Resources Management Specialist), and Sean Nelson (Climate Change Specialist).

The document was produced under the guidance of Greg Browder (Lead Water Resources Management Specialist) and supervised by Soma Ghosh Moulik (Practice Manager). The team is grateful for the feedback received from the peer reviewers: Laura Bonzanigo (Water Resources Management Specialist), Stephane Dahan (Senior Water Supply and Sanitation Specialist), Stephane Hallegatte (Lead Economist), and John Matthews (Alliance for Global Water Adaptation). Other valuable inputs were provided by Rubaina Anjum (Consultant), Pier Mantovani (Sector Leader), Gerard Soppe (Senior Water Supply and Sanitation Specialist), Lizmara Kirchner (Senior Water Supply and Sanitation Specialist), Alex McPhail (Lead Water Supply and Sanitation Specialist), Fook Chuan Eng (Lead Water Supply and Sanitation Specialist), Juliana Menezes Garrido (Senior Water Supply and Sanitation Specialist), and Gustavo Saltiel (Lead Water Supply and Sanitation Specialist). Editing and production services were provided by Steven Kennedy (Consultant) and Erin Barrett (Publishing Associate).

This work was made possible through the support of the Global Water Security and Sanitation Partnership. 



\section{Objective: Resilience}

A 2019 report by the World Bank, entitled "Lifelines: The Resilient Infrastructure Opportunity," estimated that low- and middle-income countries lose $\$ 390$ billion each year to disruptions of power, transportation, water, and telecommunications services caused by natural hazards (World Bank 2019). The disrupted services are typically delivered through large networks that are vulnerable to natural hazards over a large area. Improving the resilience of those networks would cost about 3 percent of their capital investment, but the avoided disruptions would save quadruple that amount. In other words, every dollar spent to improve resilience would avoid four dollars in costs owing to service disruptions. The cost reduction associated with spending on resilience is estimated to be $\$ 4.2$ trillion over the useful life of new infrastructure (World Bank 2019).

Infrastructure projects financed by the World Bank-such as networks for water distribution and wastewater collection, and plants for treating water and wastewater-contain components that have a long useful life, during which they are exposed to natural hazards (Smith et al. 2019; Hallegate et al. 2012). For that reason, projects financed by the World Bank typically include provisions for upgrading or expanding parts of the system, in the course of which resilience can be strengthened.

To help its clients improve the resilience of infrastructure services in the water sector, the World Bank provides technical assistance to utilities to help them improve the overall resilience of their systems and to minimize service disruptions in the face of multiple hazards, including COVID-19. Building the Resilience of Water Supply and Sanitation Utilities to Climate Change and Other Threats: A Road Map is the Bank's resource guide on this subject (World Bank 2018). The Road Map provides a broad approach to plan for and evaluate the impact of potential stressors at the system level. The present report, hereafter referred to as the Design Brief, focuses specifically on incorporating resilience into the engineering design of drinking water and sanitation infrastructure. It focuses narrowly on resilience in relation to three hazards, floods, droughts, and high winds. The focus is on these hazards because they are the main threats that climate change is expected to pose to water infrastructure.

The Road Map and the Design Brief can be applied independently, but the intent is that future Bankfunded investments will be evaluated in light of both. The Road Map should be applied first in a master planning exercise to identify priority investments. In the engineering design process that follows, those investments should be evaluated using this Design Brief. Box 1 and figure 1 provide additional detail on the complementarity of the Road Map and the Design Brief.

The primary audience of this Design Brief is World Bank task teams, utility clients, and their external engineering consultants. Its intent is to help these stakeholders better incorporate resilience into the design of water supply and sanitation infrastructure components. Task teams should verify that Bankfinanced infrastructure incorporates the resilience design principles presented here. Appendix $C$ suggests how the concepts in this Design Brief can be incorporated into the Bank's Project Appraisal Document (PAD). A sample resilience design module for use in feasibility studies and terms of reference makes up Appendix D. 
Box 1. Resilient Water Utilities and Resilient Water Infrastructure-in Three Phases

Resilience is broadly the capacity of an entity to prepare for disruption, to recover from shocks and stresses, and to adapt and grow from a disruptive event.

Water utilities face myriad potential shocks and stresses, among them extreme weather, climate change, war or terrorism, and even pandemics such as COVID-19.

Building the Resilience of Water Supply and Sanitation Utilities to Climate Change and Other Threats: A Road Map (World Bank 2018) urges water utilities to adopt a proactive approach to potential disruption that combines preparedness, emergency response, efficient operations, and long-term capital investments. Given the uncertainties about future conditions, including climate change, population growth, and economic conditions, the Road Map proses a three-phase process:

- Phase 1: Knowing the system. The process starts with participatory work to identify the vulnerable and critical elements of the system; the potential threats to those elements and the consequences of their individual or joint failure; the utility's performance objectives; and available solutions.

- Phase 2: Identifying vulnerabilities. The water system should be stress-tested in a range of plausible hypothetical scenarios to assess its likely performance. The analysis is done first on the system as it is and then repeated on the system enhanced by a variety of resiliencebuilding solutions. Performance is measured against the objectives defined in Phase 1. Analysts identify options that reduce vulnerability and improve the performance of the system and its critical elements under the same hypothetical scenarios.

- Phase 3: Choosing actions. Analysts organize the options into robust and flexible strategies and examine the trade-offs among them in meeting the objectives under the scenarios laid out in Phase 2. The options should include careful monitoring for conditions in which the system departs from acceptable performance.

This Design Brief follows the same principles, but it focuses more narrowly on the engineering of capital improvements to address climate-related natural disasters. The Design Brief assumes that the requirements for investment in each infrastructure component, such as a treatment plant or part of a distribution network, have been specified in a broader planning process-ideally one that followed the three phases above. The goal of the Design Brief is to identify risk-mitigation measures that enable the infrastructure to perform its functions even when subjected to natural hazards and to recover quickly from the effects of those hazards (figure 1).

It is not enough for water utilities to plan capital improvements well; they also must ensure that their infrastructure, before and after improvement, is resilient against natural hazards. 
BOX 1. continued

FIGURE 1. Relationship between the Road Map (phases 1-3) and the Design Brief (steps 1-6)

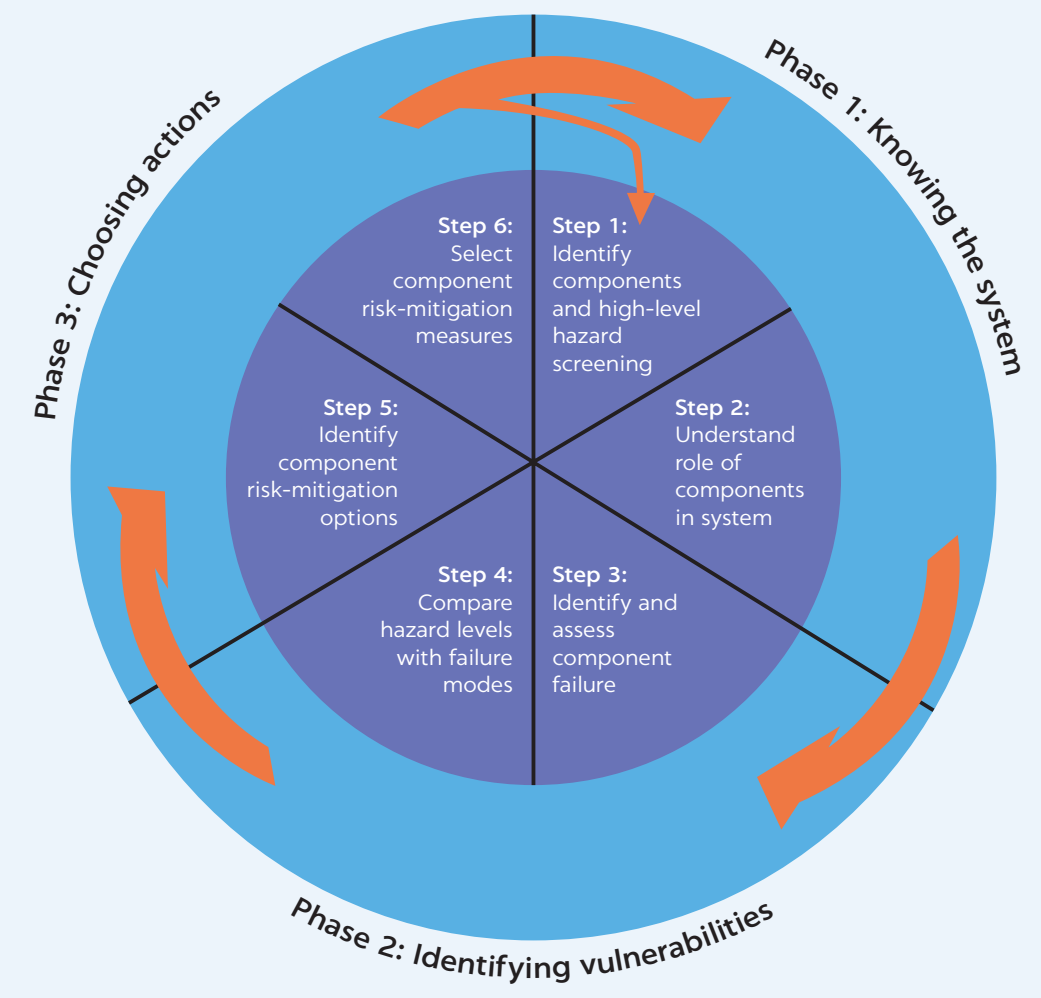

Among the additional resources developed under past initiatives to fortify water utilities are the following:

- The World Bank's Decision Tree Framework can be used to analyze the potential impacts of climate change (Ray and Brown 2015).

- The Water Utility Climate Alliance (wucaonline.org) has developed useful guidance for the application of climate research to water management, helping water utilities better respond to changes (e.g., Vogel, McNie, and Behar 2016).

- The American Water Works Association developed a comprehensive guide for analyzing and managing risks to water infrastructure stemming from terrorist attacks and natural hazards (AWWA 2010). 
The guidance lays out a process for identifying vulnerabilities and consequences and provides methods to evaluate options for reducing risk.

- The U.S. Environmental Protection Agency has prepared guidance for water utilities to become more resilient to floods (USEPA 2014) and to droughts (USEPA 2008). The agency's web-based Climate Resilience Evaluation and Awareness Tool (CREAT) assists drinking water, wastewater, and stormwater utilities in understanding and addressing climate change risks (USEPA 2019b).

- The U.S. Agency for International Development (USAID) has developed a process to assess and mitigate climate-related risks in its regional strategies (USAID 2017). The agency offers an assortment of other resources at https://www.climatelinks.org/climate-risk-management/resources-training.

This Design Brief distills concepts of traditional risk assessment, the literature on decision-making under deep uncertainty, and the results of those efforts into a practical approach to the design of resilient water infrastructure.

Application of the methodology outlined here will guide analysts in evaluating the vulnerability of system components, understanding the consequences of failure of those components on the utility's performance, and selecting suitable mitigation options to improve the resilience of the components.

Bank teams can help water utilities further improve overall system resilience-for example, by including technical assistance components in Bank-projects to support utility-wide planning that incorporates disaster risk management and climate adaptation. Such undertakings can benefit substantially from the Road Map. 


\section{Hazard Types}

Floods, droughts, and high winds are the focus of this Design Brief because they are likely to become worse with climate change and because they directly affect water infrastructure. The subsections below are not intended to provide a comprehensive description of the three hazards, but rather to present aspects of each that are pertinent to the process of resilient design.

\section{Flooding}

Flooding, the most common natural disaster in the world (CRED and UNDRR 2018), comes in a variety of forms: coastal flooding, riverine flooding, flash floods, localized flooding caused by inadequate drainage, and river blockages caused by ice jams. Significant shares of the population of low-income countries are vulnerable to flood damage, ranging from loss of property to illness and death. Climate change is expected to worsen exposure to floods because both the frequency and intensity of river floods are projected to increase in many areas. This effect would expand floodplains, increase flood depths, and make flooding events more frequent and severe. More intense rainfall can overwhelm drainage systems and cause localized flooding. Sea level rise is also a potential source of flooding in coastal areas.

The vulnerability of an infrastructure component (e.g., a water treatment plant) depends on the characteristics of the component and the severity of exposure to the flood hazard. The function of a component is affected if floodwaters reach an elevation or volume of flow above which the component cannot perform as intended. But other factors may affect vulnerability. Sometimes, performance is affected by flood-related issues that may not be associated with a specific elevation-for example, debris clogging an intake. In this case, an event of lesser severity compromises the intake because of the volume not of water but of debris. Therefore, it is useful to evaluate the impact of a variety of events to assess the vulnerability of a component.

Because of their function within a water system, many components need to be near rivers, lakes, or coastlines. Examples are intakes for water treatment plants and entire wastewater treatment plants. This means that components lie in floodplains and are thus vulnerable to floods. Damage may be caused by inundation of the component, the force of fast-flowing water, or loss of service from other components (USEPA 2014).

\section{Drought}

Droughts are different from other disasters in their onset and duration. While flooding and high winds come on quickly and last for hours to weeks, drought can take weeks to be recognized and then can persist for months or years. Droughts are difficult to predict, with respect to both their occurrence (it is hard to know when a dry spell becomes a drought) and their duration. These characteristics require a long-term approach to the evaluation of drought hazards, particularly because an official decision to declare a drought triggers the mobilization of a set of measures and actions to address the emergency. 
The decision to declare the end of the drought is equally complex. While there are overall indicators to measure drought severity-for example, the Palmer Drought Severity Index (Alley 1984)-the process by which such indicators are used must be location-specific and science-based. Agreement is needed on the indicators (e.g., precipitation, temperature, surface-water levels, reservoir volume, and soil moisture) that will be used to trigger the declaration of a drought. Water utilities should monitor these indicators before a drought is declared (e.g., reservoir levels) to prepare for a potential water shortage.

The most significant impact of droughts is a reduction in the amount of water that a utility can deliver to users. This reduction can trigger conservation measures, ranging from water-use restrictions to service interruptions over large areas. In this sense, the most severe consequences of drought manifest themselves at the system level. Nevertheless, there are localized impacts on individual components as well. For example, intakes may cease to be submerged if the water level drops below a given minimum elevation, affecting the performance of the raw water pumps and possibly causing mechanical problems. Drought may lower groundwater levels so that well pumps operate inefficiently and suffer mechanical damage. The distribution network may also lose efficiency as the increased variability in hydraulic behavior deviates from design conditions (Fontanazza et al. 2008). Pipes may suffer damage due to low water pressure.

Droughts also harm wastewater treatment systems. For example, when water-conservation measures are imposed, flows to the wastewater treatment plant drop and influent contaminant concentrations increase. This can damage equipment, adversely affect the treatment process, raise treatment costs, and lower effluent quality (Tran, Jassby, and Schwabe 2017). Less effluent also reduces the volume of water available for recycling.

When flows decline, sedimentation of solids and wastewater stagnation begin to occur in sewer pipes. Stagnation results in anaerobic conditions and generates acids that corrode pipes and gases such as hydrogen sulfide that cause odors and pose health and safety hazards. Monitoring and management of solids is necessary to keep sewage moving toward the treatment plants, adding to operational costs.

Climate change is expected to worsen droughts in many parts of the world, in terms of intensity, duration, and frequency of occurrence. Floods and droughts are related hazards. 1 As temperatures rise, more moisture evaporates from land and water bodies. When rain falls on drought-stricken areas, the drier soils have lost the texture that would allow them to infiltrate the water, thereby increasing the risk of flooding. Attempts have been made to estimate the impact of climate change on droughts, for example Li, Ye, and Yan (2009).

\section{High Winds}

High winds can occur in the form of tropical cyclones, tornadoes, or straight-line winds. Wind speeds increase with terrain elevation; for instance, wind gusts are stronger over mountain ridges and cliffs. Also, tropical cyclones intensify with warm water temperatures, availability of moisture, and lack of land friction-for example, over small islands with low-lying terrain. 
Tropical cyclones in the Western hemisphere are classified by the Saffir-Simpson Hurricane Wind Scale into five categories of increasing severity (Schott et al. 2019). Each category is characterized by a sustained wind speed range. Category 3 and above involve wind speeds greater than 178 kilometers per hour and are considered major hurricanes, although lesser hurricanes still can cause considerable damage. In the western North Pacific, the term "super typhoon" denotes a tropical cyclone with sustained wind speeds of greater than 150 kilometers per hour.

The Enhanced Fujita (EF) scale estimates the severity of tornadoes. Used predominantly in Canada and the United States, it has six categories (EFo to EF5), each characterized by a wind speed range (NOAA 2014). Rather than being assessed by wind speed, tornadoes are rated based on the damage that actually occurs. Therefore, it is possible that a tornado could receive a different rating depending on the place of occurrence and the components affected. For example, a given tornado may be given an EFo rating because it caused light damage in a rural area with few and dispersed buildings; but a tornado of the same force would be rated EF4 if it caused devastating damage in an urban area with dense infrastructure.

The vulnerability of a water infrastructure component to this hazard depends on its exposure to highvelocity winds. An elevated water storage tank may collapse during high wind, whereas an underground tank may be unaffected. High winds can destroy buildings that house critical functions in treatment plants. Buried water lines, hydrants, and sewers will break if nearby buildings are destroyed. This type of damage can occur anywhere in the service area. Also, damage to overhead power lines, substations, and other electric grid infrastructure often results in a loss of power to water utilities. Chemicals and other supplies may be dispersed by wind. Wind-borne debris can damage various components. The debris left by a high-wind event can clog collection systems (USEPA 2019a). High winds can also endanger the health and safety of utility workers, especially when they are performing emergency repairs.

Generally, all structures built in new projects will be designed according to industry-standard wind codes, for example ICC (2018). Existing infrastructure can often be retrofitted to meet code specifications. However, these procedures require knowledge of peak-gust speeds, which are the result of statistical analysis of geographic wind-speed records. Because climate change is expected to increase the severity of high-wind effects, components are likely to become more vulnerable in the future, rendering designs that meet codes based on historical records will be less effective.

It should be noted that tropical cyclones can produce storm surges in low-lying areas; therefore, the damage a component suffers could be the result of both hazards combined. Similarly, hail often accompanies tornadoes and can cause additional damage. 


\section{The Principles of Resilient Design}

The approach to resilient infrastructure design under uncertainty is different from the traditional engineering approach based on a set of design conditions. Instead of designing to meet a given standard, the goal is to seek robustness (Lempert, Popper, and Bankes 2002) across a wide range of scenarios, and to adopt flexible approaches to address the uncertainty of future scenarios (Liao 2012).

Uncertainty-based approaches allow decision-making in situations where traditional engineeringdesign standards may not be appropriate because of the lack of reliable historical data or uncertainty about the future. Typically, engineers apply design standards that are either mandated by a design code or set within a planning process. For example, a standard may require engineers to design a treatment plant to remain operational during the 100-year flood. 2 Ideally, flood hazard maps would be available to define the water surface elevations for this severe flood, rendering the engineering task relatively straightforward. However, development of such maps if they do not already exist requires a reasonably complete dataset, including historical flow or precipitation records, accurate terrain mapping, topographic and bathymetric surveys, land-cover and land-use maps, and soil maps. The data are inputs to hydrologic and hydraulic models that are used to estimate flows and water surface elevations during a flood event.

The first fundamental challenge to this approach-particularly in low-income countries, but often in middle- and upper-income countries as well-is that the necessary data may not be available. A second challenge is that, even when data are available, climate change and the highly uncertain factors mentioned above will result in impacts that are difficult to predict. Faced with these challenges, approaches that apply principles of decision-making under uncertainty (e.g., Brown et al. 2019; Hall et al. 2012) complement the traditional engineering design process.

The basic approach to resilient design is illustrated in figure 2. The process is intended to guide engineers and utility managers in the selection of measures to boost infrastructure resilience by addressing the following key questions:

- What are the consequences of component failure?

- At what hazard level is the component vulnerable to failure?

- What is the potential range of hazard levels?

- What are the costs and level of protection provided by different risk-mitigation measures?

- What residual risk exists after incorporating risk mitigation measures and what can be done should this risk materialize?

In short, because the goal of the resilient design process is to avoid bad outcomes, designers need to look first at where and how a component might fail at a given hazard level, and then consider the 


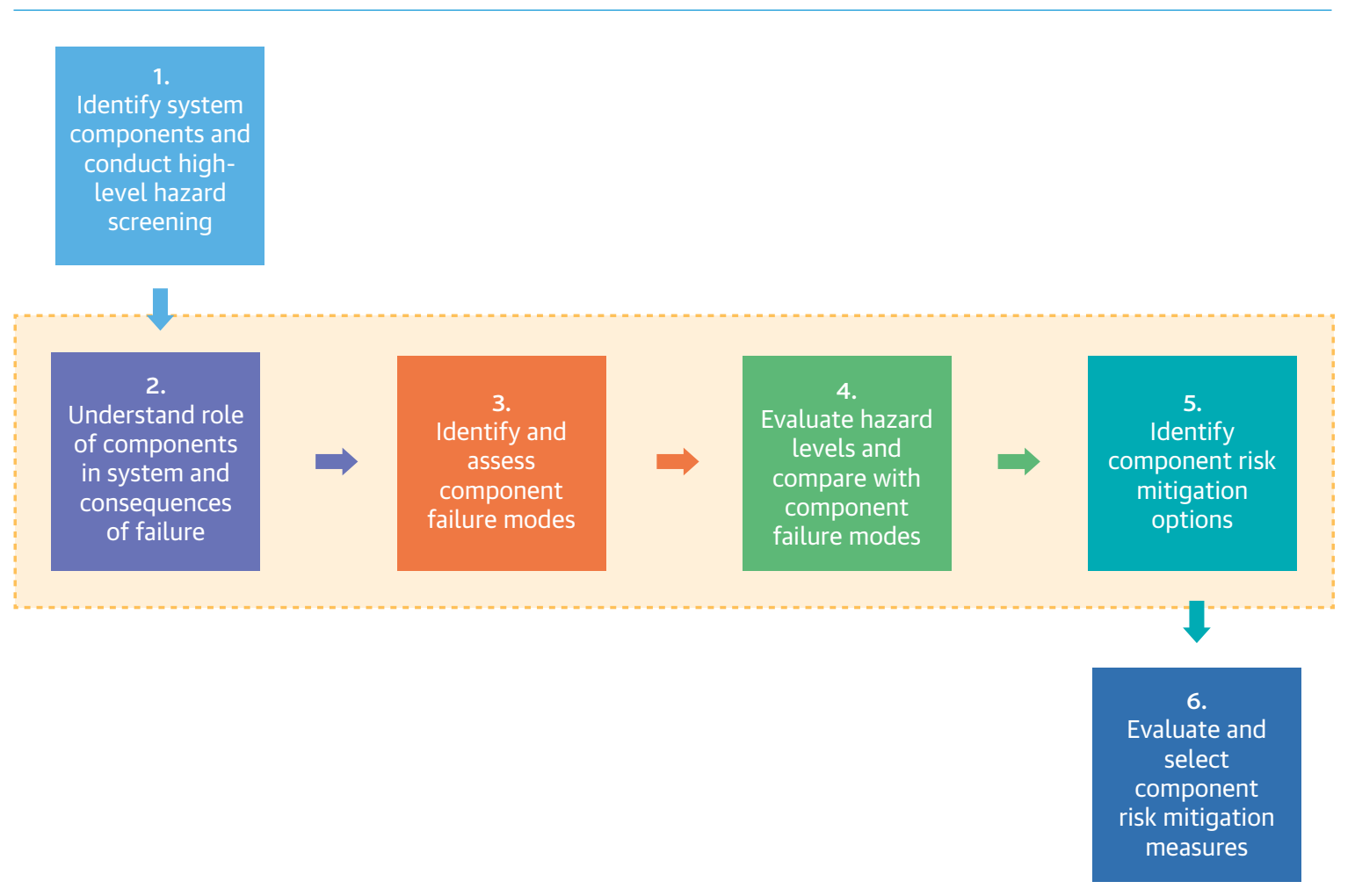

likelihood that the hazard might reach that level of severity. The steps in this general process are the subject of the next section.

The resilient design process may not be as linear as it appears from figure 2. In practice, a few iterations of Steps 2-5 may be required, as risk-mitigation solutions are examined and tested for performance. In the case of multiple hazards, Steps 3, 4, and 5 should be performed for each component and each hazard.

Among the natural hazards most likely to affect water infrastructure, climate change is paramount because it can influence the frequency, magnitude, and timing of floods, droughts, and high winds. However, other factors can add to the severity of these threats. For example, population growth affects land-use patterns and increases the extent of paved surfaces, which generate more runoff and worsen floods. In addition, demographics, land-use changes, ecological variability, water management policies, and socioeconomic and political trends can also alter the performance of water infrastructure (Mehta et al. 2019). The difficulties of predicting the nature and magnitude of these changes led to the development of approaches to support robust and flexible decision making in the water sector. The World Bank's Decision Tree Framework (Ray and Brown 2015) and UNESCO's Climate Risk Informed Decision Analysis (CRIDA) are two approaches that guide technical decision makers in formulating effective solutions (Mendoza et al. 2018). 
Flexibility and robustness can be used individually or together to improve resilience. Improving flexibility is most helpful when knowledge of uncertainties is expected to improve over time as more data are collected. Flexibility in infrastructure design may include modularity (e.g., the use of prefabricated filtration modules that can be expanded as the population served by a water treatment plant grows), expandability (e.g., including space for additional pumps in the design of an influent pumpstation's concrete pad), and other options. Furthermore, flexibility can also be incorporated through changes in operational procedures. A robust solution, by contrast, performs reasonably well against other solutions across a wide range of plausible future conditions.

Appendixes A and B contain some suggestions for actions that can be taken to determine the vulnerability of network components and potential risk-mitigation measures. However, these appendixes should not be considered an exhaustive list of options. Determining appropriate solutions is a highly context-specific undertaking and will vary considerably from project to project.

In addition to the "hard" measures that are the subject of this Design Brief, resilience at the utility level requires a series of "soft" measures (box 2) that not only improve efficiency and reliability, but actually endow the utility with the ability and resources to implement the hard measures. In fact, some of the soft measures listed in box 2 may need to be developed before hard measures can be undertaken (World Bank 2020).

Now it is time to explore in detail the six steps to resilient design of water infrastructure.

Box 2. Examples of Soft Measures to Improve Climate and Disaster Resilience

- Acquire adequate insurance coverage against natural disasters.

- Establish a program of component inventory and management.

- Develop and implement contingency and preparedness plans, including plans for continuity of operations and supply chain readiness.

- Develop water-use efficiency programs aimed at residential, commercial, industrial, and institutional users.

- Implement metering programs to support fair tariff schemes.

- Formulate realistic and fair tariffs and pursue efficient utility management.

- Enter into agreements with other utilities to improve regional resilience.

- Train staff in emergency operations.

- Develop outreach and education programs for customers.

- Conduct effective maintenance programs.

- Invest in research and development of innovative options for water supply and reuse. 
BOX 2. continued

- Identify and correct regulatory and governance weaknesses.

- Stockpile parts and supplies for emergency readiness.

- Make a master plan and update it regularly.

- Develop science-based regional drought-management plans.

- Adopt sound regulations for floodplain management.

- Improve hydrometeorological monitoring networks.

- Draw up debris-management plans.

- Develop an emergency-response plan with instructions for staff on what to do in case of a disaster.

- Develop a communication plan and an early-warning system to facilitate timely communication of relevant information on floods and droughts to officials, decision makers, emergency managers, and the public. 


\section{Six Steps to Resilient Infrastructure}

\section{Step 1. Identify System Components and Conduct High-Level Hazard Screening \\ What are the components of the water system? Are the components in locations subject to flooding, drought, or high winds?}

The first step on the path to resilient design is to determine the appropriate unit of analysis, referred to here as the "component." The component to be made resilient may be a water treatment plant, as in the examples evoked earlier, or perhaps a part of the distribution network. World Bank-financed projects typically include multiple components, and these units of analysis need to be identified in advance and standardized. The purpose of this step is to assess quickly how vulnerable the components under scrutiny are to climate change or natural disasters.

Defining components is typically straightforward. The sample water supply system illustrated by the schematic in figure 3 consists of two connected plants, one fed by a river, the other by a well field. The system has the following components: the intake, low- and high-lift pumps, the two treatment plants, storage tanks (underground and elevated), the well field, and the distribution system. Sometimes a World Bank-financed project will consist of multiple components, for example the $10 \mathrm{~m}^{3} / \mathrm{s}$ water treatment plant, the $2.5 \mathrm{~m}^{3} / \mathrm{s}$ high-lift pumps, and the elevated storage tank shown in the figure.

FIGURE 3. Schematic of A Drinking Water System

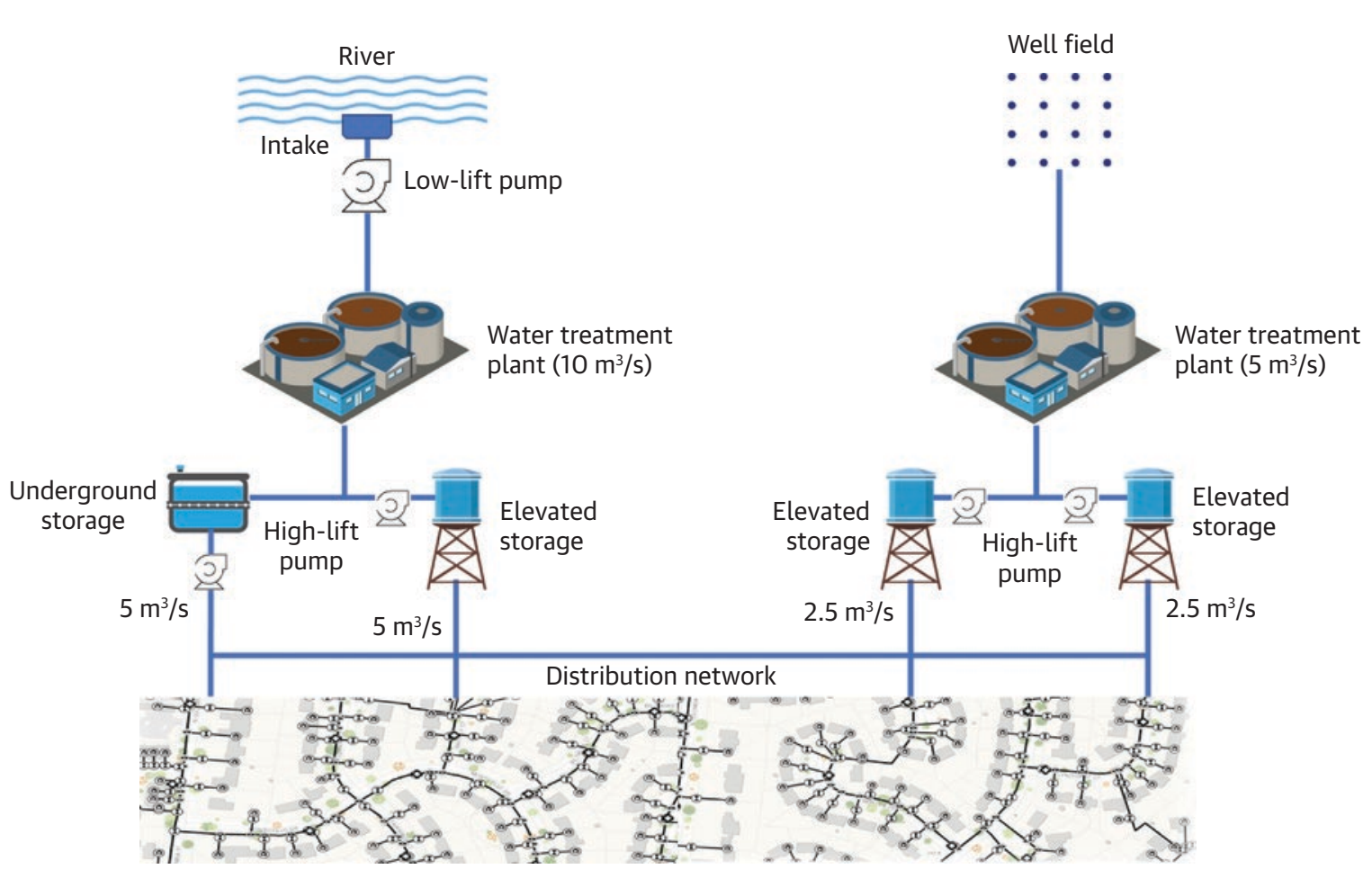


The next step is to assess quickly whether the components being scrutinized are vulnerable to climate change or natural disasters. It is likely that water infrastructure components will be subject to a variety of climate shocks, such as floods, droughts, and storms accompanied by high winds. For example, after a flood, a wastewater treatment plant may be among the last systems to recover because of its location at the lowest point of an area.

Desktop analyses are performed in this step, and various screening tools are available to guide the process. Examples are found in www.thinkhazard.org and https://climatescreeningtools.worldbank.org. Tools that provide regional information on the effects of climate change on water are also useful in this step. Examples are https://climateknowledgeportal.worldbank.org, and the climate change risk profiles for various countries published by the U.S. Agency for International Development, available at https:// www.climatelinks.org/. A compendium of leading assessment tools and approaches to water risks can be found in WWF and WBCSD (2020).

\section{Step 2. Understand the Role of Each Component in the System and the Consequences of Failure}

How does each component affect the functioning of the system? What happens to the system if the component fails?

The essence of this step is to assess the potential consequences of a given component's failure on service coverage and quality. For example, when evaluating a drinking water treatment plant, the analysis should determine what happens if it stops working, the extent to which water delivery will be affected, what areas will stop receiving water, what alternative water sources are available to supply these areas, and what all this will cost.

The consequences of the failure of a component can be divided into the costs borne by the water utility and those borne by customers. The costs to the utility include the direct damage associated with repair or replacement of the component, and the loss of revenue during service interruptions. The costs borne by customers include the social and economic costs associated with not receiving the service-for example, shutting down businesses due to lack of water or wastewater services, impacts on public health due to inadequate water and sanitation, and water damage to properties stemming from failure of the wastewater or drainage systems. Although the magnitude of damage varies by case, a general analysis indicates that service disruptions typically cost customers three times more than they cost the utility (World Bank 2019). This fact highlights the importance of water utility resilience as a key public policy issue.

Using the schematic in figure 3 as an example, the following cases illustrate the process of determining the consequences of component failure. In the examples below, it is assumed that the treatment plants fail completely, although plants could fail partially and operate at a lower level of service.

Case 1: The component under examination is a water treatment plant with a capacity of $10 \mathrm{~m}^{3} / \mathrm{s}$. If the plant fails but the water distribution network is interconnected, the entire city will need to rely on the 
connected $5 \mathrm{~m}^{3} / \mathrm{s}$ plant, probably leading to rationing. If the distribution networks are not connected (as they are in the figure), then two-thirds of the city will be without water.

Case 2: Here, the component is the well field. Let us assume that it fails owing to a region-wide drop in the water table, rendering the $5 \mathrm{~m}^{3} / \mathrm{s}$ treatment plant inoperative. If the distribution network is interconnected, then the entire city will need to rely on the $10 \mathrm{~m} / 3$ plant. An aggressive water-conservation campaign will likely be necessary. If the distribution networks are not connected, then one-third of the city will be without water.

Regional depletion of an aquifer is a long-term phenomenon; therefore, the situation in case 2 is not likely to occur suddenly. But positing it may encourage planning for an alternate source of water in anticipation of the eventual failure of the well field.

This sort of analysis is typically referred to as "network criticality analysis." It asks what happens when one component of a network fails. A significant drawback of this approach is that it does not consider what happens if several components fail simultaneously. Ideally, this sort of analysis should be undertaken for all the components of a system simultaneously to identify the most consequential elements, knowledge that could then be used to prioritize resilience investments across the utility. Therefore utility-wide resilience planning, such as that outlined in the Road Map, is an important complement to the resilience design process outlined in this Design Brief.

As noted in the cases above, the generic impact of a component failure can usually be estimated in terms of service coverage and quality. The analysis should be expanded to consider as many potential impacts as possible, such as the number of people and businesses affected, vulnerable communities that may suffer disproportionately, and the potential reduction in local economic production.

The actual costs are uncertain, of course, because they depend on how long the component will be nonfunctional; therefore, it is useful to examine ranges of possibilities. For example, sensitivity analysis can be done to estimate impacts using different periods-a day, a week, a month, and so on. This type of analysis can be undertaken by teams of engineers and economists working together, and the results incorporated into the economic analysis. Importantly, an understanding of the potential consequences of a component failure will help guide decisions on risk-mitigation investments-the more important the component, the more should be invested in improving its resilience.

\section{Step 3. Identify and Assess Component Failure Modes}

What are the vulnerabilities of a component that would lead to failure should a flood, drought, or high-wind event occur?

The goal of this step in the resilient design process is to assess the vulnerability of each of the system's component to the hazards identified in Step 1 and to understand how those vulnerabilities might affect the components' functioning. 
A component may consist of multiple elements. One of the components of the water supply system shown in figure 3 is the treatment plant, which consists of mechanical, electrical, and structural elements, each of which may fail in various ways. Some of those elements are illustrated in figure 4. Some possible findings of a vulnerability analysis conducted on that system are listed below.

- The elevated tanks could be destroyed by high winds.

- The intake could become clogged during a flood, be eroded by high-velocity flows, or cease to draw water if drought causes the water level in the river to drop sharply.

- If the treatment plant is in a flood-prone area, one or more of its processing units could become inundated, forcing the plant to shut down. For example, flood waters might erode the plant's filters.

- The treatment plant could cease to operate if electrical panels become submerged during a flood.

- The well field could become contaminated with flood waters.

- The water intake pump could be flooded

- The operations building could be destroyed by a tornado. Plant operators could be injured or killed.

- The underground distribution networks, while not directly vulnerable to any of these hazards, could suffer collateral damage from another component’s failure.

Some component failures may be easily repaired within a matter of hours; others may be more serious and result in a loss of functionality for longer periods. Failure may be partial, leaving the affected

FIGURE 4. Basic Layout of A Water Treatment Plant

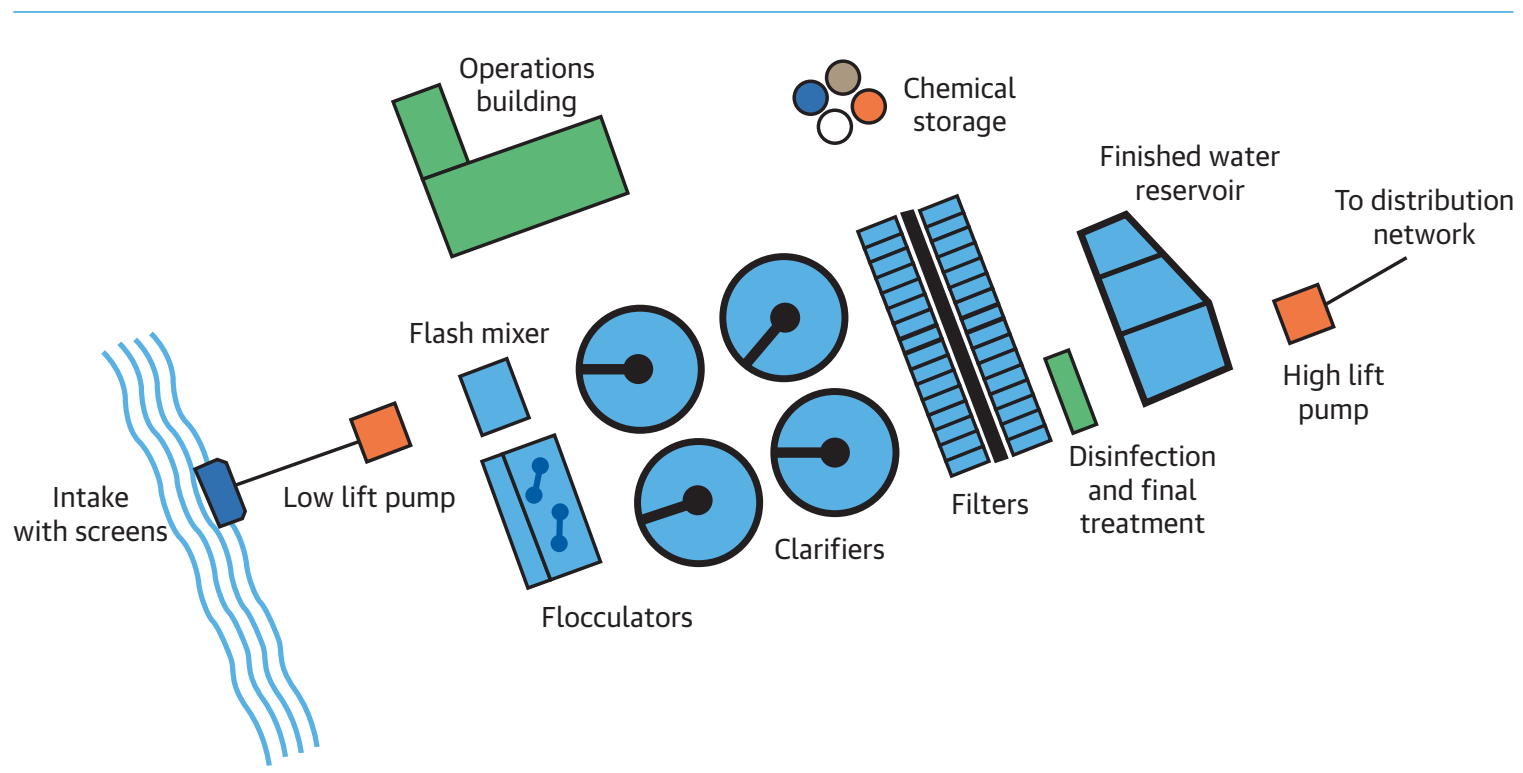


component to function in a degraded mode. For example, a water treatment plant subjected to a shock may continue to operate but produce a lower quality of treated water, which might not be drinkable from the tap, but could be purified at the household level. Appendix A provides examples of how water supply and wastewater components may fail when exposed to floods, droughts, or wind. Defining failure early in the analytical process should make these potential situations clearer. Typically, a group of stakeholders will define what constitutes failure together, conducting a trade-off analysis in the process. This is well captured in the Road Map.

The vulnerability assessment should take place before the more detailed analysis of potential hazards in Step 4. The analyst should first consider what level of hazard might cause a component to fail, and then in Step 4 examine the effects of a range of possible hazard levels. The rationale behind this bottom-up approach is that the possibility of unlikely but severe hazards is often underestimated, leaving utilities unprepared for extreme events.. In general, the analyses should cover the useful life of the component to optimize its long-term performance.

Obtaining enough information to undertake a vulnerability assessment can be a challenging process. If the component under study is new-for example, a new treatment plant-then the analyst should have access to drawings, at least at the pre-feasibility level. At this stage, the drawings may not yet contain site-specific information such as flood elevation or rainfall data, but still they may permit a preliminary assessment. When rehabilitating or upgrading old components, existing drawings can serve as the basis for a series of structured discussions with utility managers and staff. It should be noted that water utilities often do not have a complete record of the infrastructure they operate. The older the component, the more likely design documentation will be missing. Such gaps are not limited to low-income countries. The available information may not cover all aspects of the component; condition assessments and maintenance and replacement needs, particularly for underground infrastructure, may not have been recorded. Moreover, there may be unknowns, such as illegal connections of domestic sewage to the stormwater system or illegal taps into the drinking water distribution network.

In summary, to design resilient infrastructure it is the analyst's responsibility to acquire the best available information on the component. Because information may come piecemeal from various sources, the analyst must decide at what point he or she has gathered enough information to yield a reliable understanding of the component. Significant uncertainty may remain, and, as in previous steps, it may be necessary to evaluate ranges of possible outcomes. Nonetheless, the process of gathering information can reveal data gaps and prompt the utility to gather the missing data for future phases of the project.

The goal of the vulnerability analysis is not only to identify which components might fail when exposed to different hazards, but also what effect this failure might have on the functionality of the component. As noted earlier, some component failures may be quickly and easily repaired, whereas others may result in a loss of functionality for longer periods. 
Recapitulating, Step 2 examined the consequences of a component's failure on the overall water system; Step 3 examined where the component was vulnerable and the possible failure modes. Both steps are important to help guide the selection of appropriate risk-mitigation options. Tables 1-6 in Appendix A offer examples of how water supply and wastewater components may fail when exposed to floods, droughts, or high winds.

\section{Step 4. Evaluate Hazard Levels and Compare Them with Component Failure Modes} Can a potential hazard reach a level of severity such that it would cause a given component to fail?

This step estimates a range of hazard levels (for example, the magnitude of a flood) and determines whether each level could lead to the potential failures identified in Step 3. Because there is often significant uncertainty about the range of variation of a potential hazard, the analyst should define a set of plausible scenarios without putting too much confidence in the probability of occurrence, because available data are often insufficient to determine the statistical probability of the hazard. Moreover, with climate change, future probabilities may well not align with the historical data.

This step is often the most challenging in the resilient design process. In some cases, modeling can be used, but more often judgement is required in defining a suitable range of plausible hazard levels.

The following subsections summarize, by hazard, the data that may be available for use in high-level screening.

\section{Flooding}

Data on flood elevations and flow velocities, if available, can be used to determine the potential for inundation or other damage (e.g., from the waters' dynamic force or from debris, erosion, and sedimentation) on components. For example, the low-lift raw water pump that is part of the treatment plant in figure 4 operates at a certain elevation. The objective of Step 4 would be to estimate a range of flood water elevations and compare them with that of the pump. A similar evaluation would be done for electrical panels and other critical equipment.

Flood hazard data are seldom available in low- and even middle-income countries, because such datasets are expensive to assemble. If information is available, often it is only for certain areas or at coarse scales with low precision. In the absence of data, the following are alternative sources of information to characterize a flood hazard:

- Flood records from national or regional agencies. If such records are not be available for the location of interest, inferences must be made.

- Satellite or aerial images of flood events available from public sources. Such images will provide only a snapshot of a given flood event. It is also possible that evidence of major past floods will be visible in aerial or satellite photos. No information on flood depths or flow velocities will be available. 
- Consultations with experts, for example scientists and engineers in industry and academia.

- Accounts from residents on the frequency and severity of past flood events. Such anecdotal information may be affected by poor recollection and personal bias.

- Analysis of a range of hypothetical flood depths and velocities. This approach is useful in the absence of flood data and, in general, for situations involving great uncertainty. The approach examines various scenarios defined by combinations of flood depths and flow velocities for which the impacts on a given component are then estimated. This is the essence of uncertainty-based methods (e.g., Brown et al. 2019).

Climate change introduces significant additional uncertainty to an already uncertain undertaking. Even when quality watershed datasets are available, the unknowns inherent in forecasts of emissions of greenhouse gases and in the general circulation models used to predict future conditions compound. In coastal areas, the uncertain projections of sea-level rise must be considered as well. Additional ambiguities are introduced by demographics, socio-economic factors, land-use changes, and aging infrastructure. There is also the issue of data credibility, which is affected by factors such as collection and validation procedures, as well as mathematical modeling procedures to transform the collected data into hazard data. To assess impacts, therefore, the approach described in the last bullet point is usually the most advantageous, even when detailed hazard data are available.

\section{Drought}

Drought information can be as scarce as flood hazard data. However, the same types of sources-with the same caveats-can be tapped to determine whether a project may be subject to droughts.

Moreover, drought records suffer the same deficiencies as flood records, in part because, with climate change, deep uncertainty surrounds droughts just as it does floods. Thus, the same approach is recommended-that is, to assume a range of hypothetical drought severities and evaluate how individual components and systems would perform under such conditions.

In the case illustrated in figure 3 , the intake and its pump require certain minimum water levels to operate properly. The objective of this step, therefore, would be to determine a range of minimum water surface elevations in the river resulting from a range of potential drought severities. In the case of the well field, the submersible pumps in each well also require a minimum groundwater level to function properly; the function of Step 4 is to estimate how far the water table would drop in a range of droughts and compare those estimates with the elevation of the pumps.

Wind

How well can components withstand a range of potential wind speeds and durations? The typical design parameter is the speed of a wind gust of given duration-for example, a three-second gust.

Even where wind data are available, however, they do not take into account the fact that wind events are expected to become more severe with climate change. In the presence of this deep uncertainty, the best 
approach, as with floods and droughts, is to assume a range of hypothetical wind gust speeds and perform a desktop assessment of the performance of the component. For example, if a component is designed to withstand a given wind speed during a hurricane, its performance under the next greater hurricane category could be explored (AWWA 2010). When performing such assessments, it is important to realize that wind forces are proportional to the square of the wind speed (ASCE 2016); therefore, if the wind speed increases by 50 percent, the forces exerted on exposed components will increase by 125 percent.

A few tools are available to characterize high wind globally, such as the wind-hazard maps that Tan and Fang (2018) developed for tropical cyclones. Regional resources are sometimes available, such as ARA (2019) for the Caribbean. Analysts must investigate what is available in the literature to support their high-level screening.

In the case of the drinking water system of figure 3, the elevated water tanks are designed to withstand a wind load that is a function of the geographic location. The objective of Step 4 is to determine whether higher wind speeds and more severe weather are likely to result from climate change. As mentioned above, one possibility is to investigate the behavior of the tank assuming that the wind speed increases by a certain percent.

In summary, Step 4 compares the vulnerability of components with the possible ranges of severity of a given hazard. This comparison is accomplished by evaluating the hazard levels that could occur given the geographic location and other site conditions of the infrastructure and comparing those levels with the conditions that could cause one or more components to fail.

\section{Step 5. Identify Component Risk Mitigation Options}

What design options are available to reduce the chances that a component would fail should one of the hazards reach a level that triggers a failure mode?

When Step 4 reveals that it is possible for components to fail due to one or more hazards, the next step is to identify potential risk-mitigation measures to remove components from danger or to make them more resilient so that they can be back in operation as quickly as possible.

Risk-mitigation measures address the risks of component failure, either by reducing a component's exposure to hazards or by modifying it so that it can be brought back into operation more quickly. For example, one option to protect a water treatment plant from flooding would be to construct an embankment around the perimeter of plant. Flexibility can also be incorporated into mitigation measures. For example, the embankment might be built to a certain height to provide the desired level of safety, but enough space could be reserved to increase the height and width of the embankment if the effects of climate change make it necessary to increase the height. Nonstructural (soft) measures (see box 1) can also improve a component's resilience-for example, having spare parts available, training staff to repair damaged components rapidly, or changing operational modes temporarily.

The risk-mitigation measures in this section are organized by hazard. 


\section{Flooding}

There are four options for protecting components against flood risks:

1. Raise them above a specified water level

2. Relocate them outside the flood-prone area

3. Erect barriers to keep flood water from reaching components

4. Flood-proof them.

Of these, relocation can most significantly reduce the risk, but it may pose a new set of risks depending on where the component is relocated. The other three options carry a residual risk because they can fail in the event of a more severe flood. The feasibility of each depends on the nature and function of the component. For instance, relocation is often not possible, either because it is cost-prohibitive or technically unfeasible-for example, because the component must be located near a receiving water body, as is the case with wastewater treatment plants. Drinking water plants, too, are often located near a water body but need not be if it is possible to build a relatively long pipeline from the intake or if the source is groundwater.

All utilities should have the financial stability to respond and recover from a flood, which means having a fair tariff structure that supports needed expansion, upgrades, and maintenance, as well as sufficient funds to minimize service disruptions and recover quickly from a flood.

Tables 7 and 8 in Appendix B list common risk-mitigation options for various water system components. The lists are not exhaustive, but they provides a foundation to guide designer and client toward a resilient design in which water components are assessed according to attributes such as robustness, flexibility, and redundancy (Liao 2012).

Drought

In many countries drought management is reactive and thus it does not improve the resilience of the affected communities. Effective drought management must be proactive, with respect to both supply and demand (USEPA 2008; Turner et al. 2016). Measures to control water use should be accompanied by economic instruments that encourage the voluntary adoption of long-term sustainability practices (Hassan 2013).

There are several structural and nonstructural options to mitigate drought risks specific to a utility's infrastructure and operations (Chappelle et al. 2019). These measures fall into the categories of infrastructure improvements, operations and maintenance, monitoring, and financial stability.

In terms of infrastructure, water utilities can identify alternative sources of water and implement a plan to bring them online to lessen the impact of a drought. Wastewater agencies can implement alternate treatment processes to accommodate influents with higher concentrations of pollutants. 
Wastewater utilities that operate collection systems can modify sewer cleaning programs to remove sediments that accumulate as a result of slower flows. Utility managers can also explore options to increase operational efficiency and thus reduce costs.

Improved monitoring is useful for infrastructure upgrades and adjustments to operations. For water utilities, monitoring is aimed at collecting data on raw water quality and quantity. For wastewater utilities, data are needed on the quality and quantity of influent and effluent.

On the positive side, a drought provides an opportunity to detect problems in wastewater collection systems. For example, it is easier during periods of drought to detect illegal sewage discharges into the storm drain system. It is also easier to repair wastewater collection pipes to fix infiltration and inflow problems. These activities contribute to the overall resilience of the system.

As in the case of flood, all utilities should verify that they have enough funding to tend to a drought emergency.

Tables 9 and 10 in Appendix B list drought mitigation options for various water system components. As with flood mitigation options, the lists are not exhaustive, but they provide a good foundation for resilient design incorporating robustness, flexibility, and redundancy (Liao 2012).

Wind

Risk-mitigation measures for high winds center on retrofitting structures to meet the latest requirements in building codes (e.g., ICC 2018), especially those structures that house critical components such as electric controls. New structures must be designed to code specifications or better. Retrofits, too, should embody the highest possible specifications. In both cases, designers and clients must bear in mind that codes are generally based on historical records and that, with climate change, weather events are likely to worsen with time.

Wind engineering measures and construction techniques include structural bracing, straps and clips, anchor bolts, impact-resistant glass, reinforced doors, window shutters, and wind-resistant roofing materials. Other actions involve removing outdoor objects that can become windborne projectiles and securing equipment to the ground-for example, using tie-downs with ground anchors appropriate for the local soil type to secure elements such as chemical storage tanks.

Due to the short lead time and catastrophic nature of tornadoes, risk-mitigation strategies are primarily focused on reducing the risk of injury and death by providing the earliest possible warning of an approaching tornado. A suitable risk-mitigation option is to build a readily accessible tornado-safe room where utility personnel can shelter in place (FEMA 2017).

Additional measures include moving overhead power lines and other components underground, avoiding aerial extensions of water and sewer lines, improving roof coverings (e.g., avoiding ballast gravel), anchoring rooftop equipment such as air conditioning units and solar panels, and hardening the structures that house backup power equipment such as generators and fuel tanks. 
As in the case of flood and drought, all utilities should verify that they have enough funding to tend to a high wind emergency.

Tables 11 and 12 in Appendix B list risk-mitigation options for various water system components. As with risk-mitigation options for flood and drought, the lists provide a good foundation for resilient design incorporating robustness, flexibility, and redundancy should be evaluated also (Liao 2012).

\section{Step 6. Evaluate and Select Component Risk-Mitigation Measures}

Of the options available to mitigate the risk of failure, what are the options that can be selected that comply with the proposed objectives and take into account existing constraints? How does one arrive at this decision? After deciding upon which risk mitigation measures to implement, what are the residual risks and what can be done should these risks materialize?

Once a set of risk-mitigation options has been identified, the next step is to decide which of them will be implemented and when. Risks can be mitigated through engineering; however, as stated earlier, the art of resilient design is to reduce risk to an acceptable level considering cost and other site-specific constraints.

Steps 2 through 5 should facilitate the selection of appropriate risk-mitigation measures, especially lowcost measures that are clearly beneficial and flexible enough to be modified as climate conditions change. Typically, measures are selected through a process that evaluates multiple criteria-for example cost, constructability, and acceptance by stakeholders.

Arriving at Step 6, the following key issues should be well understood:

- What are the consequences of component failure?

- At what hazard level is the component vulnerable to failure?

- What is the potential range of hazard levels?

- What are the costs and level of protection provided by different risk-mitigation measures?

The objective of Step 6 is to choose among the available options and clearly articulate any remaining risks that cannot be further reduced, and a plan should be discussed for managing this residual risk. Depending on the risk tolerance of the client, the budget available, and other criteria that are suitable for a specific context, these options can be prioritized as described later in this section.

In contrast to a standard engineering process, where the design is optimized against pre-defined criteria, risk-mitigation is a search for a robust set of measures to keep components resilient over a range of plausible hazard scenarios (as opposed to a single design condition). A complementary strategy is to build flexibility into the design so that the infrastructure can be easily upgraded if, as expected, climate change makes hazards more severe over time.

The strategy for selecting risk-mitigation measures must also reflect agreement among stakeholders on what constitutes an unacceptable outcome. For instance, it may be unacceptable that a water treatment 
plant should be out of service for more than 24 hours, or that more than a given fraction of the service area should have to be supplied by trucks (World Bank 2018). Such decisions are quite site specific. Combined, the selected measures should achieve a level of resilience that avoids the unacceptable outcomes.

Other considerations that must be applied in analyzing and selecting measures are cost, practicality, constructability, operation and maintenance needs, and acceptance by stakeholders, the relative importance of which is indicated by weighting factors.

Of these considerations, cost often is the most important, and the process of resilient design always involves a trade-off between robustness and cost. To protect a drinking water treatment plant from flooding, for example, a high-cost option might be to build a floodwall around the plant. A lower-cost option would be to install a floodwater pumping system and associated conveyance to divert floodwaters away from critical processes. Both options enable similar resilience over the range of hazard scenarios; however, the latter option, though less costly, is not as robust because the mechanical equipment is less reliable than a physical barrier. In addition, pump operation requires active management in contrast with the passive nature of the floodwall. Finally, the floodwall protects against all events less severe than the design specification for the wall, whereas the pumping system will likely have to be activated for many flood events of varying severity.

The set of measures to be implemented is based on analysis of the implementation criteria mentioned above and their relative importance as indicated by the assigned weights. Various techniques of multiple criteria analysis are available for scoring and ranking the performance of a set of measures against multiple objectives. Multiple criteria analysis is widely used to evaluate water policy, strategic planning, and selection of infrastructure options (Dunning, Ross, and Merkhofer 2000; Figueira, Salvatore, and Ehrgott 2005; Hajkowicz and Collins 2007). A suitable technique should be selected to score and rank different sets of risk-mitigation measures and decide which ones will be implemented and in what sequence. As a result of this evaluation, a set of measures is identified improve the resilience of the system and its critical components.

In all cases, residual risks should be reported in association with the risk mitigation measures selected. Ideally, this risk should be quantified and included as part of the analyses carried out through a final iteration of Steps 2-5 (once the chosen risk mitigation measures have been agreed upon). In the event that residual risks cannot be quantified, a detailed qualitative description of these risks should accompany the final decision on risk mitigation measures, and if relevant, a contingency plan should be drafted to help to manage this residual risk. 



\section{Appendix A Vulnerability of System Components to Damage}

Tables 1-6 list the types of damage sustained by water and wastewater systems from flood, drought, and high wind events. (The lists are not intended to be exhaustive.) The magnitude of a disaster is often measured according to the monetary losses incurred by the service provider and the households and businesses it serves.

Disaster damage can be direct or indirect. Direct damage is physical and is typically estimated as the costs paid to repair, rehabilitate, or replace affected components. These include the costs of replacing, for example, an elevated storage tank taken down by high wind, disinfecting a well field after a flood, restoring an inlet eroded by storm waves, replacing and relocating damaged controls and instruments, and purchasing chemicals to treat turbidity.

Indirect damage encompasses the consequences of a disaster beyond physical damage to system components, and includes lost revenue, overtime wages paid to emergency-services staff, the cost of emergency equipment, and the lost productivity of residents and businesses in the service area (for example, time taken off work to deal with sewer backups or collapsed roofs). Temporary housing may be needed in the case of water damage. The environmental costs of an event-for example, the discharge of untreated sewage while a wastewater treatment plant is offline-are more difficult to monetize. Similarly, the public health impacts-for example, illness and death associated with untreated raw sewage and mold resulting from a flood-are difficult to estimate.

\section{Vulnerability to Flooding}

TABLE 1. Types of Flood Damage to Components of Drinking Water Systems

\begin{tabular}{|c|c|}
\hline Components & Physical damage \\
\hline Intakes & $\begin{array}{l}\text { Debris and excessive sediment can clog river intakes. These can suffer severe damage due to } \\
\text { impact from debris or collapse due to erosion around supporting structures. }\end{array}$ \\
\hline Wells & $\begin{array}{l}\text { Floodwaters can overtop wellheads, causing damage to the casings and contaminating the } \\
\text { well water. Shallow wells can be contaminated even if the wellhead itself has not been } \\
\text { overtopped. }\end{array}$ \\
\hline Water treatment plants & $\begin{array}{l}\text { Floodwaters can wash out open tanks and filter beds, damage mechanical equipment and } \\
\text { electrical power and controls, contaminate the treatment process and water storage, and } \\
\text { strew debris on the site. Floods can also alter sourcewater chemistry and increase turbidity, } \\
\text { requiring more demanding treatment and time. Inundated buildings are often badly damaged. }\end{array}$ \\
\hline Chemical and fuel storage tanks & $\begin{array}{l}\text { Floating debris can puncture above-ground tanks and damage their foundations. Floating } \\
\text { tanks can break free of their anchoring and spill their contents. Without chemicals or fuels, } \\
\text { services could be disrupted for a prolonged period. }\end{array}$ \\
\hline
\end{tabular}

table continues next page 
TABLE 1. continued

\begin{tabular}{ll}
\hline Components & Physical damage \\
\hline $\begin{array}{l}\text { Drinking-water distribution } \\
\text { networks }\end{array}$ & $\begin{array}{l}\text { Piping and appurtenances (e.g., fire hydrants, valves, and stream crossings) can suffer impacts } \\
\text { from debris or be washed out by fast-flowing floodwater. Distribution lines from groundwater } \\
\text { wells could be similarly affected and could also become contaminated by floodwaters. }\end{array}$ \\
\hline Water storage tanks & Tanks can be damaged by the force of floodwaters. \\
\hline Pump stations & Floodwaters can damage pumps. Dry wells can become inundated. \\
\hline Electrical controls and & Damage to or loss of these systems can affect operations (e.g., treatment processes and \\
\hline Power supply & pumping) and data collection in operational centers and treatment plants, for example \\
\hline
\end{tabular}

TABLE 2. Types of Flood Damage to Components of Wastewater Systems

\begin{tabular}{|c|c|}
\hline Components & Physical damage \\
\hline Wastewater collection networks & $\begin{array}{l}\text { Sewers can be clogged or physically damaged or experience additional infiltration and inflow } \\
\text { during a flood. Sewage can back up and flood streets, houses, and businesses. }\end{array}$ \\
\hline Lift stations & Sewage can back up, flooding houses, businesses, farmland, and roadways. \\
\hline Wastewater treatment plant & $\begin{array}{l}\text { Floods cause increased flows to the plant due to inflow and infiltration; introduce } \\
\text { contaminants into treatment processes and disrupt bioreactors; wash out primary and } \\
\text { secondary clarifiers, aeration tanks, and chlorine contact chambers; and interfere with } \\
\text { biosolids' handling and disposal. Sewage can back up and overflow into streets, houses, and } \\
\text { businesses in case of headwork failure. Buildings can be inundated by sewage. }\end{array}$ \\
\hline Chemical and fuel storage tanks & $\begin{array}{l}\text { Floating debris can puncture above-ground tanks and damage foundations. Floating tanks can } \\
\text { break free of their anchoring and move with floodwaters while spilling their contents. Without } \\
\text { chemicals or fuels, service could be disrupted for a prolonged period. }\end{array}$ \\
\hline $\begin{array}{l}\text { Electrical controls and } \\
\text { instrumentation }\end{array}$ & $\begin{array}{l}\text { Loss of these systems can impact operations (e.g., treatment processes and pumping) and } \\
\text { data collection in operational centers and treatment plants. }\end{array}$ \\
\hline Power supply & $\begin{array}{l}\text { Floods often cause power outages that can affect or shut down a treatment plant. } \\
\text { Floodwaters can enter backup generators and render them useless. }\end{array}$ \\
\hline Treated wastewater outfalls & $\begin{array}{l}\text { Floodwaters can submerge and clog outfalls with debris or sediment and erode their } \\
\text { foundations. Clogged outfalls can cause sewer backups. }\end{array}$ \\
\hline
\end{tabular}

\section{Vulnerability to Drought}

TABLE 3. Types of Drought Damage to Components of Drinking Water Systems

\begin{tabular}{ll}
\hline Components & Physical damage \\
\hline Intakes & Drought can expose submerged parts to air. \\
\hline Wells & Saltwater intrusion into aquifers. \\
\hline Water treatment plant & $\begin{array}{l}\text { Altered sourcewater chemistry and turbidity require more extensive treatment and residence } \\
\text { time. Uncertain effects of the new water chemistry on distribution system. }\end{array}$ \\
\hline Distribution network & Increased variability in hydraulic behaviors can cause deviation from design conditions. \\
\hline
\end{tabular}


TABLE 4. Types of Drought Damage to Components of Wastewater Systems

\begin{tabular}{ll}
\hline Components & Physical damage \\
\hline $\begin{array}{l}\text { Wastewater treatment } \\
\text { plant }\end{array}$ & $\begin{array}{l}\text { Drought creates low flows and influents with higher concentrations of pollutants; complicates } \\
\text { treatment. Corrosive influents can damage equipment. A higher concentration of influents can result } \\
\text { in less-effective disinfection. }\end{array}$ \\
\hline $\begin{array}{l}\text { Wastewater collection } \\
\text { network }\end{array}$ & $\begin{array}{l}\text { Sediments can accumulate with slower flows; standing and slow-moving corrosive influents may } \\
\text { damage pipes. Gas collected in pipes can become health and safety hazards. }\end{array}$ \\
\hline Lift station & Corrosive wastewater influents can damage pumps and appurtenances. \\
\hline Wastewater outfall & It becomes difficult to meet discharge limits if treatment is suboptimal, a challenge potentially \\
& compounded by lower flows in the receiving water body. \\
\hline
\end{tabular}

\section{Vulnerability to High Winds}

TABLE 5. Types of Wind Damage to Components of Drinking Water Systems

\begin{tabular}{|c|c|}
\hline Component & Physical damage \\
\hline Intakes & There can be damage from concurrent flooding (see Table 1). \\
\hline Wells & Wellheads damaged by airborne debris. \\
\hline Water treatment plant & $\begin{array}{l}\text { Inundation of open tanks and filter beds; broken mechanical equipment for electrical power and } \\
\text { controls, contaminated treatment processes and water storage, on-site debris. Destroyed buildings. } \\
\text { Restricted access to facilities because of debris and damaged roads. }\end{array}$ \\
\hline $\begin{array}{l}\text { Chemical and fuel storage } \\
\text { tanks }\end{array}$ & $\begin{array}{l}\text { Airborne debris can puncture above-ground tanks and damage their foundations. Tanks can } \\
\text { break free of their anchors and spill their contents. Without chemicals or fuels; prolonged service } \\
\text { disruptions are possible. }\end{array}$ \\
\hline $\begin{array}{l}\text { Drinking-water } \\
\text { distribution networks }\end{array}$ & $\begin{array}{l}\text { Airborne debris can strike and damage pipes and appurtenances (e.g., fire hydrants, valves, and } \\
\text { stream crossings). Networks can also be damaged if nearby buildings are destroyed. Debris strikes } \\
\text { may damage distribution lines from groundwater wells. Ruptured service lines can cause severe } \\
\text { drops in water and pressure. }\end{array}$ \\
\hline Water storage tanks & Strong winds and airborne debris can puncture elevated storage tanks . \\
\hline Pump stations & Aboveground appurtenances can be damaged by airborne debris. \\
\hline $\begin{array}{l}\text { Electrical controls and } \\
\text { instrumentation }\end{array}$ & $\begin{array}{l}\text { Control buildings can be damaged by wind- or airborne debris. The loss of systems housed in these } \\
\text { buildings can disrupt operations (e.g., treatment processes and pumping) and data collection in } \\
\text { operational centers and treatment plants. }\end{array}$ \\
\hline Power supply & $\begin{array}{l}\text { Power outages can damage or shut down a treatment plant or its components. Airborne debris can } \\
\text { break backup generators and render them useless. }\end{array}$ \\
\hline
\end{tabular}


TABLE 6. Types of Wind Damage to Components of Wastewater Systems

\begin{tabular}{|c|c|}
\hline Component & Physical damage \\
\hline $\begin{array}{l}\text { Wastewater collection } \\
\text { networks }\end{array}$ & Collateral damage from the collapse of nearby buildings. \\
\hline Lift stations & Concurrent flooding damages (see Table 1). \\
\hline $\begin{array}{l}\text { Wastewater treatment } \\
\text { plant }\end{array}$ & Wind may blow out primary and secondary clarifiers, aeration tanks, and chlorine contact chambers. \\
\hline $\begin{array}{l}\text { Chemical and fuel } \\
\text { storage tanks }\end{array}$ & $\begin{array}{l}\text { Punctured above-ground tanks; damaged tank foundations. Tanks that break free from their anchors } \\
\text { can spill their contents. Prolonged service disruptions. }\end{array}$ \\
\hline $\begin{array}{l}\text { Electrical controls and } \\
\text { instrumentation }\end{array}$ & $\begin{array}{l}\text { Control buildings can be damaged by wind- or airborne debris. The loss of systems housed in these } \\
\text { buildings can affect operations (e.g., treatment processes and pumping) and data collection in } \\
\text { operational centers and treatment plants. }\end{array}$ \\
\hline Power supply & $\begin{array}{l}\text { Power outages can shut down treatment plants and their components. Airborne debris can damage } \\
\text { backup generators or render them useless. }\end{array}$ \\
\hline $\begin{array}{l}\text { Treated wastewater } \\
\text { outfalls }\end{array}$ & Damage can result from concurrent flooding (see Table 1). \\
\hline
\end{tabular}




\section{Appendix B Risk-Mitigation Measures}

In this appendix, the cost-complexity column uses the following keys:

\$ Low cost, little complexity; can be implemented without contractors.

\$ Moderate cost and complexity; likely involves contractors.

\$\$ High cost and complexity; requires contractors.

\section{Mitigation of Flood Risks}

TABLE 7. Risk-Mitigation Options Available for Drinking Water System Components Exposed to Flood Hazards

\begin{tabular}{|c|c|c|}
\hline Component & Risk mitigation options & $\begin{array}{l}\text { Cost and } \\
\text { complexity }\end{array}$ \\
\hline \multirow[t]{3}{*}{ Intakes } & Reinforce surface-water intakes against effects of floating debris, erosion, and silting. & $\$ \$-\$ \$ \$$ \\
\hline & Install jetty or breakwater to divert debris and silt. & $\$ \$$ \\
\hline & Upgrade intake screen to minimize blockages. & $\$ \$$ \\
\hline Wells & Extend well casings and vents above the flood water elevation, waterproof well caps. & $\$-\$ \$$ \\
\hline \multirow[t]{5}{*}{$\begin{array}{l}\text { Water treatment } \\
\text { plant }\end{array}$} & $\begin{array}{l}\text { Install flood barriers (e.g., floodwalls, levees) around the plant. Install pumps if needed to } \\
\text { drain the area inside the barriers. }\end{array}$ & $\$ \$ \$$ \\
\hline & $\begin{array}{l}\text { Vertically extend walls of treatment components such as basins, tanks, and filters above } \\
\text { the design flood elevation. }\end{array}$ & $\$ \$-\$ \$ \$$ \\
\hline & Seal walls of treatment components to reduce the chance of seepage. & $\$ \$$ \\
\hline & Install monitoring equipment upstream of intakes to provide early warning of the & \\
\hline & worsening quality of raw water. & $\$ \$$ \\
\hline \multirow{2}{*}{$\begin{array}{l}\text { Chemical and fuel } \\
\text { storage tanks }\end{array}$} & Anchor tanks to counter buoyancy. & $\$-\$ \$$ \\
\hline & Install larger tanks to store additional chemicals in case of an emergency. & $\$ \$$ \\
\hline \multirow{2}{*}{$\begin{array}{l}\text { Drinking-water } \\
\text { distribution } \\
\text { networks }\end{array}$} & $\begin{array}{l}\text { Waterproof, relocate, or reinforce distribution system appurtenances (e.g., fire hydrants, } \\
\text { valve vaults). }\end{array}$ & $\$ \$$ \\
\hline & $\begin{array}{l}\text { Install or retrofit distribution lines across streams sufficiently below the streambed to } \\
\text { reduce the potential of erosion. }\end{array}$ & $\$ \$-\$ \$ \$$ \\
\hline \multirow{2}{*}{$\begin{array}{l}\text { Water storage } \\
\text { tanks }\end{array}$} & Elevate or relocate finished water tanks. & $\$ \$ \$$ \\
\hline & Reinforce the foundation and supports of elevated tanks that are in a floodplain. & $\$ \$-\$ \$ \$$ \\
\hline \multirow[t]{4}{*}{ Pump stations } & Install submersible pumps or waterproof pump motors. & $\$ \$$ \\
\hline & Elevate pump stations above the design flood level. & $\$ \$ \$$ \\
\hline & Relocate or elevate groundwater well-field pump houses that are in the flood zone. & $\$ \$ \$$ \\
\hline & Install permanent flood barriers around pump stations. & $\$ \$$ \\
\hline $\begin{array}{l}\text { Electrical } \\
\text { components }\end{array}$ & $\begin{array}{l}\text { Waterproof, relocate, or elevate motor controls, variable frequency drives, computers, } \\
\text { conduits, circuits, and electrical panels. Install redundant systems. }\end{array}$ & $\$ \$$ \\
\hline Power supply & Install generators and associated fuel tanks as a backup power supply. & $\$ \$ \$$ \\
\hline Utility & Develop a fair rate scheme that preserves utility revenues. & $\$ \$$ \\
\hline
\end{tabular}


TABLE 8. Risk-Mitigation Options Available for Wastewater System Components Exposed to Flood Hazards

\begin{tabular}{|c|c|c|}
\hline Component & Risk mitigation options & $\begin{array}{l}\text { Cost and } \\
\text { complexity }\end{array}$ \\
\hline \multirow[t]{2}{*}{$\begin{array}{l}\text { Wastewater } \\
\text { collection networks }\end{array}$} & $\begin{array}{l}\text { Correct infiltration and inflow problems to reduce flows to the treatment plant during a } \\
\text { flood. }\end{array}$ & $\$ \$ \$$ \\
\hline & Install separate sewers for rainwater and for sewage. & $\$ \$ \$$ \\
\hline \multirow[t]{5}{*}{ Lift stations } & $\begin{array}{l}\text { Replace a below-grade lift station with an above-grade one elevated above a specified } \\
\text { ("design flood") level. }\end{array}$ & $\$ \$ \$$ \\
\hline & Replace dry-well lift stations with submersible ones. & $\$-\$ \$$ \\
\hline & Elevate vents above the design flood level. & $\$ \$$ \\
\hline & Install permanent flood barriers, e.g., levees, floodwalls, or sealing doors. & $\$-\$ \$$ \\
\hline & $\begin{array}{l}\text { Install backflow prevention devices and emergency overflow measures to reduce likelihood } \\
\text { of inundation. }\end{array}$ & \\
\hline \multirow[t]{4}{*}{$\begin{array}{l}\text { Wastewater } \\
\text { treatment plant }\end{array}$} & $\begin{array}{l}\text { Install flood barriers (e.g., floodwalls or levees) around the plant. Install pumps if needed } \\
\text { to drain the protected area. }\end{array}$ & $\$ \$ \$$ \\
\hline & Upgrade screens in the headworks to reduce the chance of debris blockages. & $\$ \$$ \\
\hline & $\begin{array}{l}\text { Vertically extend the walls of treatment components such as clarifiers, basins, and tanks } \\
\text { above the design flood elevation. }\end{array}$ & $\$ \$ \$$ \\
\hline & Seal the walls of treatment components to reduce the chance of seepage. & $\$ \$$ \\
\hline \multirow[t]{2}{*}{ Pumps } & Install submersible pumps or waterproof pump motors. & $\$ \$$ \\
\hline & Elevate pump stations above the design flood level. & $\$ \$$ \\
\hline \multirow{2}{*}{$\begin{array}{l}\text { Chemical and fuel } \\
\text { storage tanks }\end{array}$} & Anchor tanks to counter buoyancy. & $\$-\$ \$$ \\
\hline & Install larger tanks to store additional chemicals in case of an emergency. & $\$ \$$ \\
\hline $\begin{array}{l}\text { Electrical } \\
\text { components }\end{array}$ & $\begin{array}{l}\text { Relocate, elevate, or waterproof electrical components (e.g., motors, switchgears, motor } \\
\text { control centers, cathodic protection systems, and exhaust fans) above the design flood } \\
\text { elevation. }\end{array}$ & $\$ \$$ \\
\hline Power supply & Install generators with fuel tanks as backup power supply. & $\$ \$ \$$ \\
\hline \multirow{3}{*}{$\begin{array}{l}\text { Treated wastewater } \\
\text { outfalls }\end{array}$} & Reinforce outfalls against the impact of floating debris, erosion, and siltation. & $\$ \$$ \\
\hline & Install jetty or breakwater to divert debris and silt away from outfall. & $\$ \$ \$$ \\
\hline & $\begin{array}{l}\text { Install check valves and emergency overflow measures to reduce likelihood of sewer } \\
\text { backups and plant inundation. }\end{array}$ & $\$ \$$ \\
\hline Utility & Develop a fair rate scheme that preserves utility revenues. & $\$ \$$ \\
\hline
\end{tabular}

\section{Mitigation of Drought Risks}

TABLE 9. Risk-Mitigation Options Available for Drinking Water System Components Exposed to Drought Hazards

\begin{tabular}{llr}
\hline Component & Risk mitigation options & Cost and complexity \\
\hline Intakes & Increase inspection and maintenance to avoid and correct problems \\
& early. & $\$ \$$ \\
& Identify and develop alternate sources of surface water. \\
\hline
\end{tabular}


TABLE 9. continued

\begin{tabular}{|c|c|c|}
\hline Component & Risk mitigation options & Cost and complexity \\
\hline \multirow[t]{2}{*}{ Wells } & Relocate well field to avoid saltwater intrusion. & $\$ \$$ \\
\hline & Identify and develop alternate sources of groundwater. & $\$ \$$ \\
\hline \multirow[t]{4}{*}{ Water treatment plant } & Develop procedures to adapt to sourcewaters with higher pollutant & \\
\hline & loads. & $\$ \$$ \\
\hline & Install capacity to manage extreme changes in influent quality. & $\$ \$$ \\
\hline & $\begin{array}{l}\text { Increase monitoring of sourcewater to detect short- and long-term } \\
\text { trends. }\end{array}$ & $\$ \$$ \\
\hline \multirow[t]{4}{*}{ Distribution network } & Install additional pumping and storage equipment to manage extreme & \\
\hline & swings in hydraulic performance. & $\$ \$ \$$ \\
\hline & $\begin{array}{l}\text { Develop agreements with other water utilities to coordinate emergency } \\
\text { response measures. }\end{array}$ & $\$ \$-\$ \$$ \\
\hline & Install additional storage. & $\$ \$-\$ \$$ \\
\hline \multirow[t]{6}{*}{ Utility } & Develop a fair rate scheme that preserves utility revenues. & $\$ \$$ \\
\hline & Reduce nonrevenue water. & $\$ \$$ \\
\hline & $\begin{array}{l}\text { Develop regional drought management planning with neighboring } \\
\text { utilities. }\end{array}$ & $\$ \$$ \\
\hline & Develop early warning system for droughts. & $\$$ \\
\hline & Implement drought risk education programs for customers on proper & \\
\hline & behavior during water shortages. & $\$$ \\
\hline
\end{tabular}

\section{Mitigation of Risks Posed by High Winds}

TABLE 10. Risk-Mitigation Options Available for Wastewater System Components Exposed to Drought Hazards

\begin{tabular}{ll}
\hline Component & Risk mitigation options \\
\hline $\begin{array}{l}\text { Wastewater } \\
\text { treatment plant }\end{array}$ & Modify treatment process to allow for higher concentrations of influents. \\
\hline Wastewater & Increase frequency of sewer inspection and cleaning. \\
collection network & $\begin{array}{l}\text { As part of pipe rehabilitation and replacement work, replace old materials with corrosion- } \\
\text { resistant ones. } \\
\text { Install equipment for moving solids through the collection system. }\end{array}$ \\
\hline Lift station & $\begin{array}{l}\text { Increase frequency of inspections. } \\
\text { Retrofit existing equipment with corrosion-resistant alternatives. }\end{array}$ \\
\hline Wastewater outfall & $\begin{array}{l}\text { Negotiate conditions for less-stringent effluent discharge limits in cases of extreme } \\
\text { drought. }\end{array}$ \\
\hline Utility & Develop a fair rate scheme that preserves utility revenues. \\
\hline
\end{tabular}


TABLE 11. Risk-Mitigation Options for Drinking Water System Components Exposed to Wind Hazards

\begin{tabular}{|c|c|c|}
\hline Component & Risk mitigation options & $\begin{array}{l}\text { Cost and } \\
\text { complexity }\end{array}$ \\
\hline \multirow[t]{2}{*}{ Wells } & Provide protection around wellheads. & $\$ \$$ \\
\hline & Remove nearby objects that could become windborne projectiles. & $\$$ \\
\hline \multirow{7}{*}{$\begin{array}{l}\text { Water treatment } \\
\text { plant }\end{array}$} & Develop and implement a quick-restart plan after a high-wind emergency. & $\$ \$$ \\
\hline & Retrofit buildings to meet wind engineering code requirements. & $\$ \$ \$$ \\
\hline & Anchor or relocate rooftop equipment. & $\$$ \\
\hline & Build tornado-safe room for utility personnel to shelter in during an emergency. & $\$ \$$ \\
\hline & $\begin{array}{l}\text { Build protective structures around critical equipment to reduce likelihood of puncture by } \\
\text { wind-borne debris and projectiles. }\end{array}$ & $\$$ \\
\hline & $\begin{array}{l}\text { Inspect underground finished water storage facility and address any issues that may allow } \\
\text { contamination during an emergency. }\end{array}$ & $\$-\$ \$$ \\
\hline & Remove objects that could become wind-borne projectiles. & $\$$ \\
\hline \multirow{2}{*}{$\begin{array}{l}\text { Chemical and fuel } \\
\text { storage tanks }\end{array}$} & Anchor tanks. & $\$$ \\
\hline & Build protective structures to reduce the possibility of puncture by wind-borne projectiles. & $\$$ \\
\hline \multirow{2}{*}{$\begin{array}{l}\text { Drinking-water } \\
\text { distribution } \\
\text { networks }\end{array}$} & Avoid aerial extensions. & $\$ \$$ \\
\hline & $\begin{array}{l}\text { Develop and implement a plan to manage severe water and pressure loss due to ruptured } \\
\text { service lines. }\end{array}$ & $\$ \$$ \\
\hline \multirow{2}{*}{$\begin{array}{l}\text { Water storage } \\
\text { tanks }\end{array}$} & Retrofit elevated tanks to the wind engineering code. & $\$ \$$ \\
\hline & If possible, replace elevated tanks with underground ones. & $\$ \$ \$$ \\
\hline Pump stations & Build protective structures to reduce the possibility of damage by wind-borne projectiles. & $\$$ \\
\hline $\begin{array}{l}\text { Electrical } \\
\text { controls and } \\
\text { instrumentation }\end{array}$ & Retrofit to code buildings that house these instruments. & $\$ \$$ \\
\hline Power supply & Build protective structures for backup power supply equipment and fuel. & $\$ \$$ \\
\hline \multirow[t]{2}{*}{ Utility } & Develop a fair rate scheme that preserves utility revenues. & $\$ \$$ \\
\hline & Negotiate interconnections with neighboring utilities. & $\$ \$$ \\
\hline
\end{tabular}

TABLE 12. Risk-Mitigation Options Available for Wastewater System Components Exposed to Wind Hazards

\begin{tabular}{ll}
\hline Component & Risk mitigation options \\
\hline $\begin{array}{l}\text { Wastewater } \\
\text { collection networks }\end{array}$ & $\begin{array}{l}\text { Avoid aerial extensions. } \\
\text { Develop and implement plans in the event that sewers rupture. }\end{array}$ \\
\hline Lift stations & Build protective structures to reduce possibility of damage by wind-borne projectiles. \\
\hline Wastewater & Develop and implement a plan to restart the plant quickly after the high-wind emergency. \\
treatment plant & Retrofit buildings to meet wind-engineering code requirements. \\
& Anchor or relocate rooftop equipment. \\
& Build shelter-in-place tornado-safe room for utility personnel. \\
& Build protective structures around critical equipment to reduce the possibility of puncture \\
& by wind-borne projectiles. \\
& Remove objects that could become wind-borne projectiles.
\end{tabular}


TABLE 12.continued

\begin{tabular}{ll}
\hline Component & Risk mitigation options \\
\hline $\begin{array}{l}\text { Chemical and fuel } \\
\text { storage tanks }\end{array}$ & $\begin{array}{l}\text { Anchor tanks. } \\
\text { Build protective structures to reduce the possibility of puncture by wind-borne projectiles. }\end{array}$ \\
\hline $\begin{array}{l}\text { Electrical } \\
\text { controls and }\end{array}$ & Retrofit the buildings housing these instruments to code. \\
$\begin{array}{l}\text { instrumentation } \\
\text { Power supply }\end{array}$ & Build structures protecting backup power supply equipment and fuel. \\
\hline $\begin{array}{l}\text { Treated wastewater } \\
\text { outfall }\end{array}$ & See Table 7 for options to mitigate concurrent flooding. \\
\hline Utility & Develop a fair rate scheme that preserves utility revenues. \\
\hline
\end{tabular}





\section{Appendix C Suggested Enhancements to the Project Appraisal Document (PAD)}

The World Bank's Action Plan on Climate Change Adaptation and Resilience (2019) commits the Bank to promote adaptation and resilience-building proactively through policy dialogue and lending operations. Water utilities throughout the world are now focusing on resilience, both in their strategic planning process and in infrastructure design. Resilience is now a core tenet of the World Bank's "Water Utilities of the Future" program. As previously noted, the World Bank's "Building the Resilience of Water Supply and Sanitation Utilities to Climate Change and Other Threats: A Road Map" (2018) provides guidance on how a utility can improve its resilience at the system level. This Design Brief provides a conceptual framework for planning and designing specific infrastructure components. Resources are cited in the references.

The objective of Appendix $C$ is to guide task teams through discussions on resilience in a Project Appraisal Document (PAD). How is resilience being integrated into project design? Documenting the integration of resilience design will assure stakeholders-including national governments, World Bank management, and the World Bank Board-that resilience-related issues have been properly addressed. The PAD template does not have a stand-alone section for resilience, although it does devote sections to technical, financial, economic, social, and environmental assessments. This appendix provides ways to address these several resilience dimensions.

It is now World Bank policy that every PAD should consider resilience in a systematic and comprehensive manner. The Bank task team, of course, has the flexibility and professional responsibility to address resilience and related issues in a manner suitable for the project. The guidance provided below should facilitate this presentation.

\section{Sectoral and Institutional Contexts}

The following general issues are addressed:

- Does the sector understand the climate and disaster risks according to global, national, and local resources and databases; have the key knowledge gaps been identified?

- How well developed is the disaster risk-management system? Are natural hazards well understood, for example, through flood hazard maps that convey historical flood frequency information? Does the disaster monitoring and response system work well-that is, are there reliable systems in place to forecast floods and monitor droughts? In the event of disaster-such as storms, floods, or droughts-does the emergency management system function well, allowing critical infrastructure such as power and roads to come quickly back online? 
- Are there policy, law, regulation, and/or technical guidelines requiring water utilities to incorporate climate resilience and adaptation into the utility planning process? For example, in some countries, water utilities are required to consider potential climate change impacts and to have a structured process in place for risk and resilience planning.

\section{Project Description}

The team should first evaluate whether resilience should be part of a project's development objectives. To the extent possible, a project should include a component or subcomponent that clearly improves the water utility's resilience at the systems level. This could take a number of forms, including:

- If a project finances an upgrade of the utility's Master Plan, the plan should reference the incorporation of resilience and adaptation into the plan.

- The project may support a stand-alone "Risk and Resilience Plan" that includes a systematic evaluation of the utility's vulnerabilities along with measures planned to reduce risks. This would include a description of the plan and how it incorporates resilience metrics when identifying risk-reduction measures.

- The project may support the development or improvement of a utility's Emergency Response Plan.

\section{Appraisal Summary}

This section of the PAD summarizes the evaluation of an appraisal; supporting documents should contain more detailed information.

Technical Analysis

A summary assessment at the utility level would describe a utility's overall vulnerability to natural hazards. Such an assessment would also identify events where natural hazards (or man-made ones, such as conflict) disrupted service, explain the potential for future catastrophic events, and identify their potential costs. It would evaluate the extent to which a utility is prepared to address these challenges and indicate how the project will help the utility address gaps or shortcomings.

For project-financed infrastructure, indicate whether a "resilient design process" (as outlined in this Design Brief) has or will be utilized. The high-level screening process (Step 1) should be completed prior to appraisal, and the PAD should name specific hazards. Given that the feasibility study (or detailed infrastructure design) occurs during implementation, consider using the following general approach:

- Scenario 1: If a feasibility study/detailed design was completed prior to appraisal, then the PAD should note the use of resilient design. If a resilient design process was not followed, then the PAD 
should indicate how resilience will be addressed during implementation, for example, in the detailed design stage or through a review of the existing design and retrofitting where necessary.

- Scenario 2: If a feasibility study/detailed design does not exist prior to appraisal, then the PAD should confirm that a resilient design process will be utilized during project implementation.

\section{Economic and/or Financial Analysis}

The methodologies for incorporating resilience into the economic and financial analysis of projects are emerging and developing rapidly. The following suggestions provide ideas for simple analyses, which should, to the extent possible, be supplemented with more advanced approaches depending on the information and resources available.

Indicate whether an analysis has examined the potential impacts of a disruption of service due to a natural or man-made hazard in either the economic or the financial analysis. The PAD should present the general results of the analysis, assuming it provides useful information. In the actual financial and economic analyses, it is suggested that the following lines of analysis be considered:

A. At the water utility level, identify past service disruptions owing to natural hazards (or manmade hazards, such as conflict) and present to the extent possible actual impacts on service coverage and service quality, including the number of people affected and the duration of service disruption. The economic analysis can offer qualitative or quantitative assessments in various terms (e.g., public health, avoided costs, or economic activity). The financial analysis can look at lost revenues and the costs of damage. Although this approach is based on past events, it suggests the benefits of a resilient water utility and helps justify investments in resilience planning and more resilient infrastructure design. If resources and time permit, the analysis could also identify plausible scenarios for serious service disruptions and assess their likely impacts.

B. For project-financed infrastructure, the team should attempt to undertake Steps 1 and 2 of the Resilient Water Utility Infrastructure Design Brief by appraisal, and consider the role of infrastructure in the system and the consequences of failure. Different scenarios regarding disruption of service coverage and quality due to component failure could be considered, and these scenarios may be examined in the economic and financial analyses. For example, if the project-financed water treatment fails, what are the economic and financial consequences of inoperability for one day, one week, or one month? The analysis will need to determine what is feasible in each project context, and the exercise should be considered more of a sensitivity analysis than a prediction. If time and resources allow, the team could also undertake a risk analysis of the different proposed investments utilizing uniform distributions in order to avoid characterizing probabilities. 


\section{Key Risks}

If natural or man-made hazards pose a key risk to the water utility and/or the project-financed infrastructure, explain the risks and how the project will mitigate them. Incorporate this dimension in the Technical Design section of the Systematic Operations Risk-Rating Tool. This section should clearly indicate any residual risks that could not be further reduced via risk mitigation measures associated with project preparation and/or implementation. While these residual risks cannot be reduced at this particular point in time, the residual risk should be identified and potentially mitigated at a later stage. Finally, these residual risks may be informed by the financial and/or economic analysis. 


\section{Appendix D Sample Resilience Design Module and Task Descriptions for Use in Feasibility Studies and Engineering Terms of Reference for World Bank-Funded Projects}

Instructions to the Task Team/Client appear in italics.

\section{A. Background}

The resilience analysis described in this document is meant to comprise one module or task. The analysis could be part of a broad feasibility study or it might undergird engineering design contracts for infrastructure investments that are financed by a World Bank operation. Another application is for longer-term master planning or investment-planning exercises. This guidance is meant to ensure that the consultant has sufficient background and understands the steps involved in producing a thorough analysis of the climate and disaster risks associated with the design of a given project. The task team should also ensure that the analysis provides enough background on all aspects of the project, even if not directly related to resilience; these indirect aspects will vary with each operation.

The World Bank's vision to eradicate extreme poverty by 2030 and promote shared prosperity by boosting the income of the lower 40 percent of households in the wealth distribution of every country depends on access to clean water and adequate sanitation.

Reaching this goal is complicated, however, by the uncertainties surrounding climate change and its impacts on water infrastructure. The World Bank believes bold action is necessary to deal with the effects of a warming planet-effects that threaten to put prosperity out of reach to millions while rolling back decades of development. By improving its focus on resilience work, the World Bank will increasingly view its business activities through a climate lens.

Over the past few years, the World Bank Group has developed several resilience-related guidance documents. Such documents include the Decision Tree Framework, which was adapted to water supply and sanitation utilities in the recent publication Building the Resilience of WSS Utilities to Climate Change and Other Threats: A Road Map (hereafter referred to as the Road Map). The new Resilient Water Infrastructure Design Brief (hereafter referred to as the Design Brief) builds upon these documents to apply resilience principles directly to the design of Bank-financed infrastructure.

\section{B. Objective of Resilience Analysis}

Users should ensure that all the tasks associated with the consultant's assignment are adequately captured in the terms of reference. The guidance below is meant to address only those aspects of the consultancy that directly apply to resilience, including efforts to address climate change and to identify disaster risks on projects. To the extent possible, the pertinent tasks should be streamlined into the prefeasibility and/or feasibility studies. 
The overall objective of the module/task is to ensure that climate change and disaster risks are adequately considered with respect to [project title] in an interactive and participatory manner. The consultant should work closely with [the client and/or task team] to understand and analyze the associated risks to service delivery and how to minimize these risks through risk-mitigation measures.

Users should select and pursue one or both options below, depending on the need of the given project.

Objective of systems-level analysis: The objective of this assignment is to analyze resilience at the utility systems level to see how specific infrastructure projects are ordered within that system. This analysis should assist with schedule investment planning for the [project title] project and illustrate the ways in which climate change and other risks might affect overall system performance by broadly applying the Road Map.

Objective of infrastructure-level analysis: This assignment involves resilience-design analysis on the infrastructure component(s) supported by the [project title] project. This analysis should first seek to demonstrate how the infrastructure component(s) themselves are responsive to climate change and other risks and then highlight the ways in which the component might fail to deliver services; resilience can be improved in such scenarios with broad application of the Design Brief.

Users should note that, ideally, the detailed infrastructure-level design and corresponding resilience analysis should be informed by and take place after systems-level analysis and a look at investment planning priorities. The infrastructure analysis can also, however, be undertaken independently in projects where the infrastructure component (s) have already been selected and are in the design phase. In these cases, the project should undertake a systems-level analysis as a form of technical assistance informing future investments of the system.

\section{Scope of Work}

The Scope of Work section should begin with details about needed design and analysis that do not relate to resilience. Resilient design is not a stand-alone thing; rather is built into the broader terms of reference by which the consultant will be hired. The text below is meant to guide task teams, utilities, and their consultants to embed resilient design into the larger engineering design and planning processes. The text below provides a brief overview of analysis at the systems and infrastructure level. The, task teams are nevertheless urged to provide the client/utility/consultants with the full Road Map and the Design Brief so they have enough information about these methodologies. For projects that consider resilience only at the level of infrastructure design, the systems-level analysis section can be deleted. It is suggested, however, that systems-level analysis be revisited.

The consultant will work in close collaboration with the [client and/or Bank's project task team] to deliver the analysis outlined below. It may also be necessary to work in collaboration with ]. 
Again, template users should select and pursue one or both options below, depending on the needs of the given project.

\section{Systems-Level Analysis}

The Road Map should be used as the guiding document for performing the systems level resilience analysis. The scope of work for this analysis includes conducting an iterative three-phase analytical exercise to scrutinize the systems level resilience of the broader water network within which [project title] operates, focusing on the climate change and disaster risks (as well as other vulnerabilities) that potential infrastructure investments in the system face to understand which investments to prioritize for maintaining system performance and increasing resilience. This analysis is an iterative process that requires the consultant to work with [the task team, local government, and other stakeholders throughout the process].

\section{Phase 1: Knowing the system}

Phase 1 consists of identifying the dimensions the system needs to perform an adequate analysis. This involves consultation with an extensive team including planners, operators, and other stakeholders. This process should identify the critical system elements , the potential threats to the system, the analytical tools on hand, the consequences of failure, and the performance objectives used to measure success. By identifying these items, the consultant will be clear about how to begin the analysis.

\section{Phase 2: Identifying vulnerabilities}

Following Phase 1, the consultant will stress-test the water system over a range of plausible future conditions and assess its performance under different scenarios. The analysis should begin with the existing conditions (i.e., the status quo) and then by simulating various different climatic and other conditions. This phase should be iterated multiple times to test different design modifications and potential solutions. The results of stress-testing should be measured against the metrics for success defined in Phase 1. Identify options in ways that reduce vulnerability and improve the performance of both the system as a whole and the critical elements within the system.

\section{Phase 3: Choosing actions}

Working with the analytical results from Phase 2, the consultant should identify the options considered and analyzed and describe how they performed under iterative stress-testing. In consultation with stakeholders, the consultant would then discuss the tradeoffs between the various options to provide additional context. The options should be able to improve a system's resilience (or a system's critical elements) by making it more robust or flexible, or both. Monitoring parameters should also be developed to track whether a system is moving outside the defined bounds within which performance is acceptable.

Infrastructure Level Analysis

The Design Brief should be used as a broad guide for performing the infrastructure-level analysis. The scope of work would include a six-step analytical exercise to inform the design of the [project title]'s 
related infrastructure. This analysis is an iterative process that requires the consultant to work with [the task team, local government, and other stakeholders] throughout the process.

The six-step process would:

\section{Identify the network components and perform high-level hazard screening}

This step involves determining the appropriate unit of analysis. This is driven in part by which piece(s) of infrastructure is directly financed by the World Bank. It should be noted, however, that World Bankfinanced projects typically include multiple network components, and the resilience analysis should address all of them. In this step, an assessment should be performed of the pertinent network component(s) to determine to which climate change or natural hazard related risk (e.g., flood, drought, wind, storms, etc.) the infrastructure is vulnerable.

\section{Understand the role of the network component within the system and consequences of failure}

The second step of the process should clearly demonstrate the importance of the Bank-financed infrastructure as it relates to the function of the system. This step should indicate the criticality of the component and the impact its failure would have on the system. The consultant will have to demonstrate the resilience of the individual component, but this step is critical to achieve broad resilience. The analysis should indicate the consequences of the component's failure both in terms of service delivery and quality.

\section{Assess the vulnerability of the elements in the network component}

This step should identify the failure modes of the World Bank-financed infrastructure. This analysis builds on the high-level hazard screening performed in Step 1 and expands it to understand specifically how the component is most likely to fail. The results of this assessment will inform the component's final design by illuminating the most likely failure scenarios against which resilience should be improved.

\section{Evaluate hazards}

This step is meant to identify the hazard thresholds that cause the failures discovered in Step 3. Given the uncertainties exacerbated by climate change, this will require analyzing a range of potential future conditions. The consultant should not put confidence in probabilities but should instead consult with experts, locals, historical records, and model scenarios to identify a range of plausible future conditions against which to analyze the network component.

\section{Identify potential risk-mitigation measures}

This step seeks to identify design options that will improve the resilience of the World Bank-financed infrastructure to climate and disaster risks. Based on the analytical findings of the previous steps, the potential risk-mitigation measures should help address the hazards to which the infrastructure is most

vulnerable as well as to address the failure modes that have been identified. These potential risk mitigation measures should then be analyzed to assess how they make the network component more resilient to the hazards identified in previous steps. 


\section{Select risk-mitigation measures}

The consultant should select the measures that best mitigate risk from all theoptionsidentified in Step 5. Prior to the selection of specific risk-mitigation measures, the consultant should have demonstrated that the options were adequately analyzed with respect to the hazards and risks considered earlier and at a broader level. The selection should balance efficacy and cost via meetings with [decision-makers and stakeholders]. The selected measures should then be incorporated into the design of the infrastructure and clearly specify how the risk mitigation measures can be implemented and the potential impact they may have on the overall design and construction. After selecting risk mitigation measures, the consultant should also provide estimates of residual risks. This is important so that decision makers understand the trade-offs associated with the remaining risks. It also leaves open the possibility of implementing residual risk mitigation measures at a later stage in the process, provided that the conditions permit this (e.g., budgets, political will, social/environmental challenges, etc.).

The consultant should follow the [Road Map and/or the Design Brief] to ensure that resilience is adequately analyzed at the [system level (Road Map) and/or the network component level (Design Brief)].

\section{Tasks}

The tasks outlined below are tailored to conducting the systems-level analysis in particular. Still, there is substantial similarity in the types and general progression of tasks needed for conducting the infrastructure level analysis, and the first steps of this analysis require understanding the system. Thus, to detail the tasks involved in applying the guidelines of the Design Brief, users of this template should refer to steps 1-6 in section $C$, immediately above, and situate the tasks below into these steps. It is important to contextualize and adjust these to relate to the specific component(s) financed by the project and the associated engineering design process.

In general, activities include data collection and assimilation, model development, vulnerability assessment, risk management planning, general report writing and presentation of findings, and collaboration with the client and project teams, including through periodic audio and/or video meetings. The tasks will include, but not necessarily be limited to, the following:

1. Review existing information, designs, and other proposed developments. These will be provided by the client with support from the World Bank team and other stakeholders involved, upon request by the selected consultant prior to the initiation of work and should include, but not necessarily be limited to, the following:

a. Hydrometeorological data, including station type and location, historical station data series, global meteorological and surface hydrology datasets, existing hydrologic, as well as groundwater wells, aquifer, and water-quality data series as pertinent to the analysis.

b. Estimations of population changes, projections, and other relevant socioeconomic historical data. 
c. Interventions and proposed investments in the system, and spatial and hydrological characteristics of the system located in the study area.

d. Spatial data and characterization of natural and artificial recharge zones and groundwater.

e. Existing water balances and estimations of water dynamics in the system.

f. Characteristics of infrastructure networks of interest (water supply, sanitation, drainage), and hydraulic features.

g. Spatial layers of historical water leaks and costs.

h. Existent hydrologic models or hydraulic models in the region.

i. Demographic and demand projections and land-use trends in the region.

2. Data collection:

a. Hydrological/meteorological data, including station type and location, historical station data series, global meteorological and surface hydrology datasets, existing hydrologic, water quality and water resources system models, region and model/data assimilation products, as well as groundwater well, aquifer, and water quality data series as pertinent to the present study.

b. Re-analyses of data and other secondary sources derived from remotely sensed observations.

c. Long-term monthly historic streamflow, runoff series, and meteorological, water quality, and groundwater data from different points in the area.

d. Location and characteristics of major existing reservoirs, hydraulic works, and infrastructure such as tunnels, intakes, sand traps, canals, levees, dikes, treatment plants, river training and other structural and nonstructural works, well fields, green infrastructure, and others.

e. Structured documentation of system characterization and configuration, such as in extant and established water system databases, Google Docs, and ArcGIS.

f. Development of a basic connectivity map, derived from available system schematics, as well as descriptions (and universal physical science principles) of the functioning of these structures. The conceptual map of infrastructure connectivity will enable model verification and serve as the basis for a statistical model.

g. Characterization of demographic projections, demand patterns, shifts in land use, and other social and economic trends relevant (as identified) in the region.

h. Time series on water demand and other characteristics of users in the area. 
i. Location and characteristics of sewage and wastewater disposal points.

j. Location and characteristics of water supply network.

3. Data structuring and analysis: Organize the data and structure the documentation of the system's characteristics and configurations so it matches the existing client's water-system database, Google Docs, and ArcGIS platforms.

4. Stakeholder consultation:

a. Identify the project stakeholders participating in the study.

b. Analyze the proposed interventions (including natural infrastructure) of the basins and their measurable deliverables contributing to the objectives of the analysis; this will identify critical interventions that can be incorporated in the proposed portfolios. These include:

(1) Existing proposals that stakeholders would like the consultant to include in their analysis, and the solicitation of other information to include.

(2) Characteristics of the social and political context that would help determine the ideal locations for interventions as well as the most important issues to address in each region of interest.

c. In consultation with the counterpart, consult with identified stakeholders to select the key climatic risk factors and to define and select the project performance indicators.

5. Performance indicators:

a. Propose indicators of performance that could be aligned with the design to promote resilience, robustness, reliability, maximum performance, supply during droughts, mitigation of flood and wind exposure and risk, analysis of benefits and costs, and mitigation of social impacts, and others, and also suggest how they should be measured according to the proposed objectives of a systemslevel analysis.

b. Evaluate the suitability of the proposed alternatives.

c. Based on the performance metrics agreed with the stakeholders, documents reviewed, and data collected, determine those indicators showing adequate project performance as a basis for arranging alternative indicators. Performance indicators should be defined by name (or characteristics), description, and unit(s).

6. Development of climatic scenarios:

a. Develop weather generators or other tools to generate stochastic time series; these could be used to facilitate a climate stress test for the system. 
b. Develop demographic, land use, water demand, and other scenarios relevant to the system's functioning and dynamics.

7. Assessment of potential climate sensitivities:

a. Produce a detailed plan for rapid system scoping that tests its sensitivity to climate change, using perturbation methods to evaluate the elasticity of runoff and recharge to precipitation and temperature changes, and the elasticity of the selected performance indicators to changes in runoff.

b. Apply the climate-sensitivity analysis derived from the rapid system scoping; discuss the results with the client and project team and other key stakeholders. Together decide on which factors of the robustness analysis of the system should be performed.

8. Climatic robustness analysis for the system:

a. Create a robustness analysis as a stress test for sampling climate-related inputs to the hydrologic/ system, modeling workflow in a controlled process; the process would reveal which changes to system performance can be directly attributed to specific changes in climatic conditions.

b. Follow a bottom-up approach (such as in the Decision Tree Framework and Road Map), emphasizing the vulnerability of the system's performance (based on the selected project performance indicators/metrics) by parametrically or stochastically varying climate factors (precipitation and temperature) using a weather generator or other similar methods to simulate likely traces that include characteristics and conditions of interest for the performance of the system, plus a coupled system model to define the failure region, and then elaborating situations based on these vulnerabilities (the selection of the anticipated range of changes in the climate parameters can be aided by portals such as the World Bank Climate Change Knowledge Portal, the Nature Conservancy's Climate Wizard, or others).

c. Compare the results of a low-risk situation (including low impact and few indications from General Circulation Model or Regional Climate Model projections, historical occurrences and trends, paleo records, expert opinions, etc., that future conditions might fall within the "failure domain") with a high-risk situation (high impact and many indications of likely future conditions under which failure could occur).

d. Use the indicators defined earlier in the process, including robustness, resilience, and other things, to evaluate the system's design and that of proposed alternatives. If set thresholds are not met, see if robustness and resilience can be achieved through direct prefeasibility or feasibility design modifications. This is done by repeating the system analysis with the proposed modifications and then propose those modifications for a robust and resilient design. If the alternatives are deemed too risky (or options for design modifications are limited), discuss other adaptations with the client. If the uncertainty is so great it precludes a conclusion, evaluate the possible application of advanced 
tools for decision-making under uncertainty such as Robust Decision Making, Dynamic Adaptive Policy Pathways, Robust Optimization, and others.

9. Develop a portfolio of activities to improve resilience:

a. Prioritize interventions and strategies and develop a risk-management action and adaptation plan, with related costs, for the system under analysis. Even after selecting options for improving resilience, there will be some level of risk remaining. These residual risks should be clearly articulated in the reporting of these prioritized interventions and strategies.

\section{E. Deliverables/Specific Outputs Expected from the Consultant}

The deliverables and outputs should be amended or modified to align with the stage of the project's design when utilizing this sample module, as well as the relevant resilience analysis (infrastructure or systems level, or both). These generic deliverables are illustrative only, but they generally align with what would be expected for either of the resilience analyses being pursued by the task team/client.

1. Inception report by the end of the [ ] month after initiation of the respective work, including an updated and detailed work plan, methodology, models, and tools to be used, and timeline as agreed with the World Bank team and/or client.

2. Preliminary report for revision and comment by the World Bank team to be incorporated back into the analysis via iteration prior to the final report, by the end of the [ ] month after initiation of the respective work.

3. Final report addressing the comments and observations from the World Bank team, two weeks before the end of the contract by the end of the [ ] month after initiation of the respective work.

4. Other informal communications regarding progress of the study, as agreed with the World Bank team.

5. Presentations, as needed, to illustrate the advances and results of the study (dates to be determined).

All deliverables should demonstrate that the consultant has worked closely with [the utility, task team, and other pertinent stakeholders] and that the analyses were adequately iterative to consider the impacts of proposed design changes against identified hazards.

\section{F. Duration of the Assignment and Place of Work}

The contract will be from to It is expected that the work will be primarily performed in the consultant's place of residence. Trips to the project area and to World Bank's headquarters in Washington, DC, will likely be necessary.

Frequent communication with the World Bank staff and clients will be maintained for the assignment's duration. 


\section{G. Qualifications}

Pertinent qualifications should be added to ensure the consultant's ability to perform the work beyond resilience analyses.

The principal personnel of the consultant assigned to the study should have a strong background in water supply and sanitation infrastructure engineering and/or management. At least one member of the team should have a strong background in water resources economics. Knowledge about alternative methods of risk-based decision-making and adaptation of vulnerable water systems considering the effect of uncertain information, especially the effects of climate change, is a must. Knowledge and prior experience in using other climate change and/or resilience analyses will be beneficial. Experience working with the Bank in applying decision-making under uncertainty (DMDU) methodologies is an advantage. The consultant should have experience in compilation and analysis of natural hazards, climate, and economic data. Familiarity with previous World Bank publications on resilience and/or climate change, including, but not limited to, the Design Brief and Road Map is extremely advantageous. The consultant should also have experience using water and sanitation system models. The principal personnel to be assigned to the study should have an academic degree, preferably at the PhD level (or Master of Engineering), as well as fluent spoken and written English.

\section{H. Annex}

In addition to the guidance presented above, template users should provide a summary of the project that is pertinent to the overall assignment, including the aspects related to resilience analysis and any past studies that have informed infrastructure prioritization. The terminology should also align with these terms of reference once the specifics are developed. Finally, the task team should ensure that any reference to resilience guidance documents are appropriate to the project. 


\section{Glossary}

Component

Deep uncertainty

Element

Failure

Flexibility

Level of service

Network

Reliability

Resilience

Robustness
A physical part of a water system, e.g., an intake or a water treatment plant.

A situation in which decision makers do not know or do not agree on the models relating actions to consequences or the probability distributions for the input parameters critical to those models.

For purposes of this publication, components may consist of multiple elements. For example, a water treatment plant comprises elements such as the intake, flocculators, clarifiers, filters, pumps, and others.

The state of a component when its level of service falls to a level at which water users are adversely affected. The conditions for failure are generally defined by decision makers in consultation with experts.

The ability to modify a current direction to adapt to changes. For example, storage of an emergency supply of water-treatment chemicals in case water quality exhibits significant changes.

How utility managers and operators wish a system to perform over the long run, including technical, managerial, and financial aspects.

A component of a water system comprised of pipes of various configurations and spatially distributed throughout the service area, e.g., a sewage collection network.

The probability that a system, component, or element will perform its intended functions adequately for a given period or will operate in a specified environment without experiencing service failure.

The capacity of an entity to prepare for disruptions, to recover from shocks and stresses, and to adapt and grow from a disruptive event. In this Design Brief, resilience is applied as a blend of flexibility and robustness that allows for adjustments to risks, stresses, shocks, threats, and new conditions.

The ability to endure a range of stresses without the need to adapt. Robust solutions are those that are good (though not necessarily optimal) regardless of future conditions. 
Risk

Risk mitigation

Sensitivity analysis

Shock

Stress

System

Threat

Vulnerability
A measure of potential loss that results from the chance of occurrence of a hazard, the value of components exposed to the hazard, and the vulnerability of those components.

Applied to measures intended to correct a deficiency that could cause a component failure due to the occurrence of a hazard. In this Design Brief, risk mitigation is used in a similar manner as climate adaptation.

An analysis to investigate how different levels of severity of a hazard affect a component of a system.

A sudden or unexpected hazard event that has the potential to disrupt normal functions and threatens human life and property.

A factor that makes the effective operation of a system more difficult, including limited financial resources, poor management, or impacts from climate change and disaster risks. Stresses can also be chronic conditions, including poverty, urbanization and pollution, and climate conditions that can affect services.

An assembly of components to deliver a service, e.g., a water supply system.

A factor that could negatively affect the performance of a system. Threats can come from a range of sources, including natural hazards, demographics, and environmental factors.

The propensity of a system to be adversely affected. Vulnerability encompasses sensitivity or susceptibility to a hazard and lack of capacity to adapt. 


\section{Notes}

1 Climate change affects the distribution of rainfall such that most places are becoming wetter during the rainy season and drier during the dry season. Beyond the relation between flood and drought hazards, it is possible to examine how these trends may interact. This issue is beyond the scope of this document.

2. The "100-year flood" is a term used to designate a flood event that has a 1 percent chance of occurring in any given year. The magnitude of this event-that is, the flow and water surface elevation at a given location-are either already specified in design procedures or can be estimated through engineering analyses based on historical measurements. The 100-year flood is a common target in traditional engineering design.

3. The "Decision Tree Framework" (World Bank 2015) discusses the "bottom-up" approach in detail. 



\section{References}

AECOM. 2018. Climate-Resilient Water Infrastructure: Guidelines and Lessons from the USAID Be Secure Project. Washington, DC: United States Agency for International Development (USAID).

Alley, W. M. 1984. "The Palmer Drought Severity Index: Limitations and Assumptions." Journal of Climate and Applied Meteorology 23 (7): 1100-09.

ARA (Applied Research Associates). 2019. Development of Design Wind Speed Maps for the Caribbean for Application with the Wind Load Provisions of ASCE 7-16 and Later. Washington, DC: Pan American Health Organization.

ASCE (American Society of Civil Engineers). 2016. Minimum Design Loads and Associated Criteria for Buildings and Other Structures. ASCE/SEI 7-16. Reston, VA: ASCE.

AWWA (American Water Works Association). 2010. Risk Analysis and Management for Critical Asset Protection (RAMCAP®) Standard for Risk and Resilience Management of Water and Wastewater Systems Using the ASME-ITI RAMCAP Plus Methodology. Washington, DC: ACME Innovative Technologies Institute.

Badura T., S. Ferrini, M. Agarwala, and K. Turner. 2017. Valuation for Natural Capital and Ecosystem Accounting. Synthesis report for the European Commission. Norwich, United Kingdom: Centre for Social and Economic Research on the Global Environment, University of East Anglia.

Brown, C., F. Boltz, S. Freeman, J. Tront, and D. Rodriguez. 2020. "Resilience by Design: A Deep Uncertainty Approach for Water Systems in a Changing World." Water Security 9 (April): 100051.

CRED (Centre for Research on the Epidemiology of Disasters) and UNDRR (United Nations Office for Disaster Risk Reduction). 2018. Economic Losses, Poverty \& Disasters 1998-2017. Brussels, Belgium: CRED.

Chappelle, C., H. McCann, D. Jassby, K. Schwabe, and L. Szeptycki. 2019. Managing Wastewater in a Changing Climate. San Francisco, CA: Public Policy Institute of California.

Dunning, D. J., Q. E. Ross, and M. W. Merkhofer. 2000. "Multiattribute Utility Analysis for Addressing Section 316(b) of the Clean Water Act." Environmental Science \& Policy 3 (S1): 7-14.

Federal Emergency Management Agency. 2017. "FEMA P-320-Taking Shelter from the Storm: Construction Plans and Specifications." Washington, DC. http://www.fema.gov/library/viewRecord.do?fromSearch=fromsearch\&id=5788.

Figueira, J., S. Greco, and M. Ehrgott, eds. 2005. Multiple Criteria Decision Analysis: State of the Art Surveys. New York: Springer-Verlag.

Fontanazza, C. M., G. Freni, G. La Loggia, and V. Notaro. 2008. "Definition of Performance Indicators for Urban Water Distribution Systems in Drought Conditions." In Performance Assessment of Urban Infrastructure Services: Drinking Water, Wastewater and Solid Waste, edited by E. Cabrera and M.A. Pardo. London: IWA Publishing.

Hajkowicz, S., and K. Collins. 2007. “A Review of Multiple Criteria Analysis for Water Resource Planning and Management.” Water Resources Management 21 (9): 1553-66.

Hall, J. W., R. J. Lempert, K. Keller, A. Hackbarth, C. Mijere, and D. J. McInerney. 2012. "Robust Climate Policies under Uncertainty: A Comparison of Robust Decision Making and Info-Gap Methods.” Risk Analysis: An International Journal 32 (10): 1657-72.

Hallegate, S., A. Shah, R. Lempert, C. Brown, and S. Gill. 2012. "Investment Decision Making under Deep Uncertainty: Application to Climate Change.” Policy Research Working Paper 6193, World Bank, Washington, DC.

Hassan, R. 2013. "Drought Management Strategies in South Africa and the Potential for Economic Policy Instruments." In Drought in Arid and Semi-Arid Regions, edited by K. Schwabe, J. Albiac, J. D. Connor, R. M. Hassan, and L. M. González, 370-90. Dordrecht, Berlin, New York, and London: Springer.

ICC (International Code Council). 2018. International Building Code. Falls Church, Virginia: ICC.

Lempert, R. J., S. Popper, and S. Bankes. 2002. “Confronting Surprise.” Social Science Computer Review 20 (4): 420-40.

Li, Y., W. Ye, M. Wang, and X. Yan. 2009. "Climate Change and Drought: A Risk Assessment of Crop-Yield Impacts." Climate Research 39 (1): $31-46$.

Liao, K.-H. 2012. "A Theory on Urban Resilience to Floods-A Basis for Alternative Planning Practices.” Ecology and Society (17) 4. 
Marlow, D. R., M. Moglia, S. Cook, and D. J. Beale. 2013. “Towards Sustainable Urban Water Management: A Critical Reassessment.” Water Research 47 (20): 7150-61.

Mehta, L., S. Srivastava, H. N. Adam, Alankar, S. Bose, U. Ghosh, and V. Vijay Kumar. 2019. “Climate Change and Uncertainty from 'Above’ and 'Below': Perspectives from India.” Regional Environmental Change 19 (6): 1533-47.

Mendoza, G., A. Jeuken, J. H. Matthews, E. Stakhiv, J. Kucharski, and K. Gilroy. 2018. Climate Risk Informed Decision Analysis (CRIDA): Collaborative Water Resources Planning for an Uncertain Future. Paris: UNESCO and Alexandria, VA: International Center for Integrated Water Resources Management.

Natural Capital Coalition. 2016. “Natural Capital Protocol.” www.naturalcapitalcoalition.org/protocol.

NOAA (National Oceanic and Atmospheric Administration). 2014. “The Enhanced Fujita Scale (EF Scale).” https://www.spc.noaa.gov/efscale/.

Ray, P. A., and C. M. Brown. 2015. Confronting Climate Uncertainty in Water Resources Planning and Project Design: The Decision Tree Framework. Washington, DC: World Bank.

Sapkota, M., M. Arora, H. Malano, M. Moglia, A. Sharma, B. George, and F. Pamminger . 2015. "An Overview of Hybrid Water Supply Systems in the Context of Urban Water Management: Challenges and Opportunities.” Water 7 (1): 153-74.

Schott, T., C. Landsea, G. Hafele, J. Lorens, A. Taylor, H. Thurm, B. Ward, M. Willis, and W. Zaleski. 2019. “The Saffir-Simpson Hurricane Wind Scale." https://www.nhc.noaa.gov/pdf/sshws.pdf.

Shibuya, N., and R. Bradshaw. 2018. Resilient Water Supply and Sanitation Services: The Case of Japan. Washington, DC: World Bank.

Smith, D. M., J. H. Matthews, L. Bharati, E. Borgomeo, M. McCartney, A. Mauroner, A. Nicol, D. Rodriguez, C. Sadoff, D. Suhardiman, I. Timboe, G. Amarnath, and N. Anisha. 2019. "Adaptation's Thirst: Accelerating the Convergence of Water and Climate Action.” Background paper prepared for the 2019 report of the Global Commission on Adaptation, Rotterdam and Washington, DC. https://alliance4water.org /resources/Adaptations-Thirst-GCA-Background-Paper-Water.pdf.

Tan, C., and W. Fang. 2018. "Mapping the Wind Hazard of Global Tropical Cyclones with Parametric Wind Field Models by Considering the Effects of Local Factors.” International Journal of Disaster Risk Science 9 (1): 86-99.

Tran, Q. K., D. Jassby, and K. A. Schwabe. 2017. “The Implications of Drought and Water Conservation on the Reuse of Municipal Wastewater: Recognizing Impacts and Identifying Mitigation Possibilities.” Water Research 124 (November): 472-81.

Turner, A., S. White, J. Chong, M. A. Dickinson, H. Cooley, and K. Donnelly. 2016. “Managing Drought: Learning from Australia.” Prepared by the Alliance for Water Efficiency, the Institute for Sustainable Futures, University of Technology Sydney, and the Pacific Institute, for the Metropolitan Water District of Southern California, the San Francisco Public Utilities Commission, and the Water Research Foundation. https://pacinst.org/publication/managing-drought-learning-from-australia/.

USAID (United States Agency for International Development). 2017. “Climate Change in USAID Country/Regional Strategies: A Mandatory Reference for ADS Chapter 201.” USAID, Washington, DC.

USEPA (United States Environmental Protection Agency). 2008. "Drought Response and Recovery: A Basic Guide for Water Utilities.” EPA 810-B-18-004, USEPA, Washington, DC.

USEPA. 2014. “Flood Resilience: A Basic Guide for Water and Wastewater Utilities.” EPA 817-B 14-006, USEPA, Washington, DC.

USEPA. 2019a. “Planning for Natural Disaster Debris.” EPA 530-F-19-003, USEPA, Washington, DC.

USEPA. 2019b. “Climate Resilience Evaluation and Awareness Tool, Version 3.o Methodology Guide.” USEPA, Washington, DC.

Vogel, J., E. McNie, and D. Behar. 2016. “Co-Producing Actionable Science for Water Utilities.” Climate Services 2-3 (September): 30-40.

World Bank. 2018. Building the Resilience of WSS Utilities to Climate Change and Other Threats: A Road Map. Washington, DC: World Bank.

World Bank. 2019. Lifelines: The Resilient Infrastructure Opportunity. Washington, DC: World Bank.

World Bank. 2020. From Waste to Resource: Shifting Paradigms for Smarter Wastewater Interventions in Latin America and the Caribbean. Washington, DC: World Bank.

WWF (World Wildlife Fund) and WBCSD (World Business Council for Sustainable Development). 2020. Right Tool for the Job: Tools and Approaches for Companies and Investors to Assess Water Risks and Shared Water Challenges. Geneva: WBCSD. 



\section{GWSP}

GLOBAL WATER
SECURITY \& SANITATION

SECURITY \& SANTA
PARTNERSHIP

(4) wORLD BANK GROUP 